\title{
EL DEFENSOR DEL PUEBLO EUROPEO, QUINCE AÑOS DESPUÉS ${ }^{1}$
}

\author{
PILAR MELLADO PRADO \\ Profesora Titular de Derecho Constitucional \\ Universidad Nacional de Educación a Distancia
}

SUMARIO

I. Introducción.

II. Orígenes, reconocimiento y evolución del Defensor del Pueblo Europeo.

III. El Estatuto del Defensor del Pueblo Europeo.

IV. Ámbito de competencia del Defensor del Pueblo Europeo: los casos de "mala administración".

V. Facultades de investigación del Defensor del Pueblo Europeo.

VI. Los informes anuales del Defensor del Pueblo Europeo: su impacto.

VII. Las relaciones del Defensor del Pueblo Europeo con los Defensores del Pueblo y órganos similares: la Red Europea de Defensores del Pueblo.

\section{INTRODUCCIÓN}

Siempre he creído firmemente que un derecho vale lo que vale su garantía. En este sentido, el reconocimiento jurídico en el Tratado de la Unión Europea de la figura del Defensor del Pueblo Europeo se encuadra, por una parte, en el proceso de democratización, y por ende, de acercamiento a los

1 Este artículo es una revisión y actualización del publicado en el n. ${ }^{\circ} 15$ de la Revista de Derecho de la Unión Europea (2. ${ }^{\circ}$ semestre de 2008) bajo el título "El Defensor del Pueblo Europeo y la Agencia de los Derechos Fundamentales de la Unión Europea: perspectivas de futuro". Se ha elaborado en el marco del Proyecto de Investigación del Ministerio de Ciencia e Innovación DER 2009-10375 sobre "Constitución y Globalización. Transformaciones del Estado Constitucional y constitucionalización de espacios supranacionales". 
ciudadanos, de las instancias decisorias de la Unión, pero sobre todo, viene a reforzar el sistema de protección de los derechos fundamentales en el ordenamiento jurídico de la Unión, estableciendo nuevas garantías para el ciudadano europeo en relación con el poder público comunitario.

Como es sabido, la referencia más inmediata para el análisis de la institución del defensor del pueblo es la concepción escandinava del Ombudsman que los suecos consagraron en su Constitución de 1809. Desde entonces, esta institución ha sufrido un proceso de expansión imparable - hasta el punto de poder hablar de "universalización" de la figura ${ }^{2}$ demostrando que puede adaptarse a cualquier sistema político siempre y cuando éste se base sólidamente en principios democráticos.

Como ha sostenido reiteradamente el que fuera Defensor del Pueblo español, Álvaro Gil-Robles, este proceso de incorporación a los más diversos sistemas jurídicos aha sido llevado exclusivamente de la mano de la necesidad ${ }^{3}$. En este sentido, la compleja, poderosa $-\mathrm{y}$ claramente interventoramaquinaria administrativa de las sociedades contemporáneas, pusieron en evidencia, especialmente a partir de los años sesenta, las carencias y limitaciones de los tradicionales mecanismos de control de la actividad de la Administración Pública.

La figura del Defensor del Pueblo viene caracterizada desde sus orígenes por su clara vinculación al Parlamento, tanto en la elección como en la dación de cuentas, aunque dotada de un privilegiado estatuto de independencia (puesto que no está sujeta a un mandato imperativo); así como por permitir un acceso directo y sencillo a todos los ciudadanos, y por unos amplios poderes de investigación.

Así pues, el Defensor del Pueblo no es sólo una garantía complementaria del poder legislativo, sino también un medio más sencillo, más rápido, menos gravoso y más flexible en su funcionamiento que los recursos judiciales para controlar la legalidad de los actos y resoluciones de las Administraciones Públicas.

Ahora bien, es necesario subrayar que esta figura no pretende sustituir el control directo de los Parlamentos ni el de los Tribunales de Justicia, sino completar su labor, descargándoles de un cúmulo de asuntos que no debieran ocupar su atención innecesariamente. En este sentido, el Defensor del Pueblo, a través de sus informes, pone de manifiesto al Parlamento las carencias o defectos de una normativa determinada, así como los puntos negros en el funcionamiento de la Administración Pública, que deberían ser corregidos para no generar más quejas o procesos judiciales innecesarios ${ }^{4}$.

2 Sobre la expansión de la concepción del ombudsman, véanse: ROWAT, D.C.: The Ombudsman Plan. The worldwide Spread of an Idea, American University Press, Lanham 1985; y REIF, L. y otros (edits): The Ombudsman: diversity and development, I.O.I., Alberta, 1993.

3 GIL-ROBLES, A.: El control parlamentario de la Administración (el Ombudsman), 2. ${ }^{\mathrm{A}}$ Edición, INAP, Madrid 1981, pág. 217 y ss

4 GIL-ROBLES, A.: "El Defensor del Pueblo Europeo. De la utopía a la esperanza", en VVAA: Los derechos del europeo, Cyan, Madrid 1993, pág. 224. 
De esta forma, el Defensor del Pueblo cumple una doble función de importancia primordial: protege a los ciudadanos contra los abuso de las administraciones públicas y actúa como un factor de mejora de dichas administraciones 5 .

Además, en algunos países, como es el caso de España, se reconoce a esta figura la legitimación activa para recurrir a los Tribunales Constitucionales en defensa de los derechos y libertades fundamentales de los ciudadanos e incluso, de la constitucionalidad de las leyes ${ }^{6}$.

\section{ORÍGENES, RECONOCIMIENTO Y EVOLUCIÓN DEL DEFENSOR DEL PUEBLO EUROPEO}

En la década de los años setenta, además de algunas iniciativas en el seno del Consejo de Europa ${ }^{7}$, hay que resaltar que en el marco de la Comunidad Europea, varios diputados del Parlamento Europeo formularon diversas preguntas por escrito a la Comisión y al Consejo, sobre la posibilidad de crear un Defensor del Pueblo para la Comunidad Europea que se correspondiera con el Parliamentary Commissioner for Administration británico ${ }^{8}$ o con el modelo clásico del ombudsman escandinavo. Las instituciones comunitarias aludidas rechazaron la propuesta considerando que como los ciudadanos comunitarios podían presentar sus quejas sobre las actividades de las Comunidades a través de la propia Comisión o canalizarlas a través de las Oficinas de Información comunitarias o de un diputado, no existía la necesidad de crear un ombudsman comunitario?.

5 En este sentido, véase Moore, V.: "Peut-on évaluer le rôle des ombudsmans?", en Révue française d'Administration Publique n. ${ }^{\circ}$ 64, 1992, pág. 623-628.

6 El artículo 162.1 a) y b) de la Constitución española de 1978 legitima expresamente al Defensor del Pueblo para interponer el recuro de inconstitucionalidad y el recurso de amparo ante el Tribunal Constitucional. Sobre el Defensor del Pueblo español véase el artículo de Antonio Colomer: "El Defensor del Pueblo: un órgano político-administrativo de protección de los derechos", en Revista de Derecho Político n. ${ }^{\circ}$ 71-72, 2008, pág. 57-85.

7 Por ejemplo, la Resolución de la Conferencia Parlamentaria Europea sobre Derechos Humanos celebrada en Viena en 1971, y la Recomendación 757 de 1975 (Doc. 3516, XXVI-3) de la Asamblea Parlamentaria del Consejo de Europa relativa a las Conclusiones de la reunión de la Comisión de Cuestiones Jurídicas de la Asamblea con los Ombudsmen y los Comisarios parlamentarios en los Estados miembros del Consejo de Europa (París 18-19 de abril de 1974).

8 El Parliamentary Commissioner británico es nombrado por la Corona, a propuesta del Primer Ministro, por un tiempo indeterminado. El acceso al Parliamentary Commissioner se realiza exclusivamente a través de los miembros del Parlamento, y la intervención judicial paraliza la investigación de aquél. Por su parte, el Médiateur francés, al que también se haría referencia en algunas iniciativas del Parlamento Europeo, es nombrado por Decreto del Consejo de Ministros por un período determinado. Sus investigaciones pueden coexistir con las de las jurisdicciones competentes.

9 Véanse por su interés las preguntas escritas n. ${ }^{\circ}$ 663/74 (DOCE C 86, de 17 de abril de 1975 pág. 54) formulada a la Comisión por Lord O’Hagan y la n. ${ }^{\circ} 751 / 56$ (DOCE C 70, de 21 de marzo de 1977, pág. 14) formulada al Consejo por M. Dondelinger. 
Asimismo, el 6 de abril de 1979, el eurodiputado Sir Derek Walker-Smith presentó un Informe sobre el nombramiento de un Defensor del Pueblo Europeo por el Parlamento Europeo, basado en el trabajo de la Comisión de Asuntos Jurídicos del Parlamento Europeo, en el que se defendía "la necesidad de proteger al individuo contra la mala administración y los abusos de la autoridad pública mediante un sistema de control a la vez rápido, sencillo y eficaz ${ }^{10}$. Sobre la base de dicho Informe, el Pleno del Parlamento Europeo encargó a la Comisión de Peticiones la elaboración de otro Informe sobre el procedimiento a seguir para el nombramiento de un Defensor del Pueblo Europeo, que fue aprobado posteriormente mediante una Resolución de la Cámara ${ }^{11}$.

Este impulso decidido del Parlamento Europeo a favor de la creación de la figura objeto de nuestro análisis, y que representa claramente el "Informe Walter-Smith", no se mantuvo durante los años siguientes. En este sentido, destaca el "Informe Chanterie" y la posición de algunos miembros de la Comisión de Peticiones del Parlamento Europeo, cuyo Presidente por entonces, E. Nyborg, mostró siempre claramente su desinterés ${ }^{12}$. No obstante, el Consejo Europeo de Fontainebleau, celebrado en junio de 1984, aprobó un programa de trabajo del que surgió la creación de un Comité ad hoc "Sobre una Europa de los Ciudadanos", presidido por P. Adonnino, al que se encargó un informe (conocido como Informe Adonnino) sobre las medidas que debían adoptarse para acercar las Comunidades Europeas a los ciudadanos. Entre esas medidas, el Comité propuso el nombramiento por parte del Parlamento Europeo de un "Ombudsman" europeo, propuesta que no se incorporó al Acta Única Europea de 1986 ${ }^{13}$.

Asimismo, se reiteraron las preguntas parlamentarias a la Comisión, pero ésta seguía manteniendo que, ante las hipotéticas infracciones del Derecho Comunitario, los ciudadanos comunitarios podían dirigirse a la Comisión de Peticiones del Parlamento Europeo y a la propia Comisión, por lo que resultaba innecesaria la creación de un ombudsman europeo ${ }^{14}$.

10 Report drawn up on behalf of the Legal Affairs Committee on the appointment of a Community Ombudsman by the European Parliament, 6 de abril de 1979 (Ponente: Sir Darek WalterSmith) PE 57.508/fin. Doc. 29/79, pág. 6.

11 Résolution concernant la désignation, par le Parlement Européen, d'Ombudsman pour la CE (DOCE C 140, de 5 de junio de 1979, pág. 153). En esta Resolución, el Parlamento Europeo establecía que el Defensor del Pueblo Europeo sería nombrado por el Parlamento Europeo, si bien mantendría una independencia funcional de la Cámara, aunque no orgánica, ya que al ser un comisionado parlamentario estaría obligado a informar al Parlamento y podría ser cesado por éste. Su función consistiría esencialmente en controlar la aplicación del Derecho Comunitario por las autoridades públicas, y no sólo por las instituciones comunitarias.

12 El Informe Chanterie desaconsejaba la creación del ombudsman europeo (Documento A2/41/85, DOCE C 175, de 15 de julio de 1985) y llevó a la aprobación por el Pleno del Parlamento de una Resolución en el mismo sentido (DOCE C 175, de 15 de julio de 1985). Resulta también interesante en la misma línea el Informe de la Comisión de Peticiones (Ponente: V. Reding) PE 150.218 déf.

13 Report to the European Council by the Ad Hoc Commiitee "On a People's Europe", Milan, 28 y 29 de junio de 1985, A 10.04 COM 85, SN/2536/3/85, pág. 7.

14 Respuesta del entonces Presidente de la Comisión, J.Delors (DOCE C 123, de 19 de mayo de 1988) a la pregunta escrita formulada por B. Castle a la Comisión (pregunta escrita n. ${ }^{\circ}$ 1235/87, DOCE C 123, de 21 de septiembre de 1987). 
Este aparentemente incomprensible cambio de actitud en el seno del Parlamento Europeo no debería extrañarnos si tenemos en cuenta que la creación de una figura de estas características en los sistemas nacionales ha suscitado siempre dudas sobre su utilidad o conveniencia, dudas claramente acrecentadas en el caso comunitario por una considerable desconfianza y un importante recelo competencial de la Comisión de Peticiones del Parlamento en cuanto a las funciones que pudieran atribuirse al Defensor del Pueblo Europeo $^{15}$. Y por lo que se refiere a la Comisión y el Consejo, como instituciones afectadas directamente por una posible función de fiscalización de sus actividades por parte del Defensor del Pueblo Europeo, nada más explicable que la posición que mantuvieron reiteradamente en el sentido de que se trataba de una figura innecesaria y superflua.

Será finalmente en la década de los noventa cuando se produzca un verdadero punto de inflexión. El 4 de mayo de 1990, el entonces Presidente del Gobierno español, Felipe González, envió una carta al Primer Ministro de Irlanda - país que ostentaba en ese momento la Presidencia de la Comunidad- en la que proponía por primera vez la idea de una "Ciudadanía de la Unión", y sugería el establecimiento de mecanismos adecuados para la protección de los "derechos especiales" de los que serían sujetos los "ciudadanos europeos". Uno de esos mecanismos sería la creación de un Defensor del Pueblo Europeo como instrumento para proteger los derechos específicos de los ciudadanos europeos y contribuir a su salvaguarda ${ }^{16}$.

Esta concepción del Defensor del Pueblo Europeo, íntimamente vinculada a la ciudadanía europea, se mantendría en el Memorándum que presentó la Delegación española en la fase preparatoria de la Conferencia Intergubernamental sobre la Unión Política de 1991, bajo el título El Camino a la ciudadanía Europea ${ }^{17}$.

También la Delegación de Dinamarca presentó, el 21 de marzo de 1991, un Memorándum con las propuestas de su Gobierno a la mencionada Conferencia Intergubernamental, entre las que se incluía la creación de un ombudsman europeo ${ }^{18}$.

Por su parte, el Parlamento Europeo — a través de su Comisión de Peticiones- volvió a expresar sus reservas considerando que la creación de un

15 En tal sentido, véase MOREIRO GONZÁLEZ, C.J.: «El Defensor del Pueblo en el Tratado de la Unión Europea", en Gaceta Jurídica de la CE, Serie D, n. ${ }^{\circ}$ 19, enero de 1993, pág. 180.

16 La carta aparece citada en el Informe Anual del Defensor del Pueblo 1995, OPCE, Luxemburgo, pág. 8 .

17 European Citizenship, Spanish Delegation (21 de febrero de 1991) Anexo II, basado en la Nota de 24 de septiembre de 1990, Documento SN 3940/90, de 24 de septiembre de 1990 (Europe Documents n. ${ }^{\circ} 1653$, de 2 de octubre de 1990). En este documento, la ciudadanía europea se concibe como el estatuto personal e inseparable de los nacionales de los Estados miembros, que por su pertenencia a la Unión son sujetos de derechos y deberes especiales propios del ámbito de la Unión y que se ejercen y se tutelan específicamente dentro de las fronteras de ésta, sin perjuicio de que tal condición de ciudadano europeo se proyecte también fuera de esas fronteras. Su Anexo II incorporaba la propuesta concreta de crear un Defensor del Pueblo de la Unión Europea.

18 CONF-UP 1777/91, Bruselas, 21 de marzo de 1991, pág. 25 y 26. 
ombudsman europeo no sólo afectaría a las competencias de los defensores nacionales y comisiones parlamentarias nacionales, sino que sería "una estructura nueva que vendría a superponerse a estructuras ya existentes, tales como la Comisión de Peticiones del Parlamento Europeo, en detrimento de éstas". Reaparecía así el miedo a ver debilitadas las competencias del Parlamento Europeo y, en especial de su Comisión de Peticiones en el control de la Comisión Europea ${ }^{19}$.

No obstante, la posición del Parlamento Europeo no era unánime en este punto. Así, por ejemplo, la Comisión de Asuntos Institucionales puso de manifiesto, en un Informe provisional sobre la ciudadanía europea de 23 de mayo de 1991, que una figura de estas características podría "garantizar una importante función para velar por el respeto de los derechos de los ciudadanos frente (a las acciones administrativas) de las instituciones ${ }^{20}$.

Finalmente, el Tratado de la Unión Europea, firmado en Maastricht el 7 de febrero de 1992, reconoció en su artículo 8D, junto con el derecho a presentar peticiones al Parlamento Europeo, el derecho de todo ciudadano de la Unión a dirigirse al Defensor del Pueblo Europeo -instituido en el entonces artículo 138 E del Tratado de la Comunidad Europea- en relación con casos de mala administración en la actuación de las instituciones u órganos comunitarios, con exclusión del Tribunal de Justicia y del Tribunal de Primera Instancia en el ejercicio de sus funciones jurisdiccionales.

Se incorporaba así al ordenamiento jurídico comunitario una figura que, aunque no se incluía en el marco institucional del Tratado de la Unión ni se incluye ahora en el nuevo Tratado de Lisboa, puede considerarse una institución en sentido técnico y no un mero órgano auxiliar o interno del Parlamento Europeo ${ }^{21}$.

El Tratado blindaba los elementos esenciales que configuran esta "institución" unipersonal, tales como su elección por el Parlamento Europeo, su independencia en el ejercicio de sus funciones, su ámbito de competencias y los rasgos básicos de su procedimiento de actuación, dejando al Parlamento Europeo la fijación de su Estatuto y las condiciones generales de ejercicio de sus funciones, si bien el Tratado implica directamente en esta función a la Comisión y al Consejo al exigir el dictamen previo de la primera y la aprobación del segundo ${ }^{22}$.

19 Informe de la Comisión de Peticiones del PE sobre las deliberaciones de la Comisión de Peticiones durante el año parlamentario 1990/1991 (Ponente: V. Reding), A3-0122/91, de 3 de mayo de 1991. Doc. PE 150.218/def.

20 Informe Provisional de la Comisión de Asuntos Institucionales sobre la ciudadanía de la Unión (Ponente: Sra. Bindi) A3-0139/91, de 23 de mayo de 1991. Doc. PE 150.034/def

21 A. Ruiz Francés lo califica de "órgano sui generis" ("El Defensor del Pueblo de la Unión Europea", en Cuadernos Europeos de Deusto n. ${ }^{\circ}$ 17, 1997, pág. 98).

22 La Decisión del Parlamento Europeo sobre el Estatuto del Defensor del Pueblo y sobre las condiciones generales del ejercicio de sus funciones fue aprobada por el Parlamento el 9 de marzo de 1994 y modificada por las Decisiones de 14 de marzo de 2002 (DO L 113, de 4 de mayo de 1994 y DO L 92, de 9 de abril de 2002) y de 18 de junio de 2008 (DO L 189, de 17 de julio de 
Además, comparto plenamente la opinión de Álvaro Gil-Robles en el sentido de que al garantizarse en el Tratado de la Unión Europea el derecho a recurrir al Defensor del Pueblo en relación con los casos de mala administración —-seguramente por influencia anglosajona- se justifica que la actuación del Defensor del Pueblo "no deba vincularse exclusivamente a los supuestos de actuaciones derivadas o relacionadas con el cumplimiento de un servicio público, pues existen otras muchas actuaciones de las administraciones públicas, potencialmente irregulares, que no se vinculan o derivan directamente de una actividad de servicio público stricto sensu (...) sino también a las posibles irregularidades en el funcionamiento ordinario de las administraciones públicas, referidas tanto a una quiebra del principio de legalidad en el ámbito del ordenamiento comunitario o a una vulneración de determinados principios generales del Derecho Comunitario" ${ }^{23}$.

Según esta interpretación, y teniendo en cuenta que "hay mala administración cuando una institución u órgano comunitario no actúa de acuerdo con la ley, no respeta los principios de buena administración o viola los derechos humanos ${ }^{24}$, pueden someterse al Defensor del Pueblo no sólo las cuestiones referidas a la actuación administrativa ordinaria de la Administración comunitaria, sino también las derivadas de una vulneración de los derechos y libertades fundamentales, en general, y de los derechos específicos del ciudadano europeo, en particular, con independencia de que dicha vulneración se produzca por una acción o por una omisión o "no resolución".

Y es que no hay ninguna razón para excluir de la competencia del Defensor del Pueblo los casos en que las instituciones u órganos de la Unión no han respetado los derechos fundamentales garantizados en el Tratado de la Unión Europea ${ }^{25}$.

Ahora bien, es necesario subrayar que aunque la creación del Defensor del Pueblo Europeo responde claramente a la necesidad de completar el sistema de protección de los derechos fundamentales en la esfera de la Unión, aquél carece de legitimación procesal activa para recurrir ante el Tribunal de Justicia de la Unión Europea, y en consecuencia, dependerá de la iniciativa del Parlamento Europeo.

Por otra parte, los Tratados de Ámsterdam y Niza no introdujeron ninguna novedad en esta materia, manteniendo la redacción del originario artículo 138 E del TCE.

2008). Asimismo, el 8 de julio de 2002, el Defensor del Pueblo adoptó una Decisión por la que se adoptan disposiciones de aplicación, que sería modificada por las Decisiones del Defensor del Pueblo de 5 de abril de 2004 y 3 de diciembre de 2008.

23 GIL-ROBLES, A.: "El Defensor del Pueblo Europeo. De la utopía a la esperanza", Ob. Cit., pág. 229.

24 Algunos ejemplos de mala administración son: irregularidades administrativas, injusticia discriminación, abuso de poder, falta de respuesta, denegación de información o demoras innecesarias, en "Qué se entiende por mala administración?", en www.ombudsman.europa.eu

25 En este sentido, GOSALBO BONO, R.: "Maastricht et les citoyens: le Médiateur européen", en Révue Française d'Administration Publique, n. ${ }^{\circ}$ 64, 1992, pág. 639. 
Posteriormente, durante los trabajos de la Convención sobre el futuro de Europa, el entonces Defensor del Pueblo Europeo - y miembro de la Convención como observador- Jacob Söderman, presentó una escueta contribución sobre "El lugar del Defensor del Pueblo Europeo en la futura Constitución de la Unión Europea ${ }^{26}$. En este documento, el Defensor del Pueblo explicaba las razones por las que debía incluirse la figura del Defensor del Pueblo en la futura Constitución Europea y consideraba que aquélla debía ser mencionada en el marco institucional de la Unión, junto al Comité de las Regiones y al Comité Económico y Social. Asimismo, solicitaba que se incluyera el derecho a presentar reclamaciones ante el Defensor del Pueblo en la Sección de la Constitución referida a los derechos de los ciudadanos europeos.

Sin embargo, resulta curioso que en esta contribución específica sobre el papel del Defensor del Pueblo en la futura Constitución Europea, Söderman no reiterara la propuesta que había hecho en su discurso ante la sesión plenaria de la Convención celebrada el 25 de junio de $2002^{27}$ y en su contribución a la Convención de 26 de julio de $2002^{28}$, en el sentido de otorgar al Defensor del Pueblo Europeo la facultad de someter al Tribunal de Justicia de las Comunidades Europeas los casos de violación "de un derecho fundamental vinculante según el Derecho Comunitario" por parte de los Estados miembros o una institución u órgano comunitario, cuando a raíz de una investigación ordinaria iniciada de conformidad con el Tratado, lo considerara conveniente.

Finalmente, la non nata Constitución Europea no recogió las peticiones de Söderman de que se incluyera el Defensor del Pueblo en el marco institucional, ni siquiera en el Capítulo dedicado a "Otras Instituciones y órganos consultivos de la Unión", ni tampoco el reconocimiento de su legitimación activa ante el Tribunal de Justicia de las CCEE.

No obstante, las demás peticiones incluidas en su última contribución a la Convención fueron acepadas. Así, en el Título II de la Parte I (De los derechos fundamentales y de la ciudadanía de la Unión) se consagraba el derecho de todo ciudadano europeo a recurrir al Defensor del Pueblo (art. I-10.2); y en la Parte II (Carta de los derechos Fundamentales de la Unión) se reconocía nuevamente el derecho de todo ciudadano de la Unión y de toda persona física o jurídica que resida o tenga su domicilio social en un Estado miembro a someterle los casos de mala administración en la actuación de las instituciones, órganos u organismos de la Unión con exclusión del Tribunal de Justicia de la Unión Europea en el ejercicio de sus funciones jurisdiccionales (art. II103). Asimismo, y directamente vinculado a las funciones del Defensor del

26 CONV 466/02, Bruselas, 17 de diciembre de 2002 (CONTRIB 176).

27 Speech by the European Ombudsman, Jacob Söderman to the European Convention, 24 de junio de 2002: "El Defensor del Pueblo Europeo está preparado para asumir la responsabilidad de someter al Tribunal de Justicia de las CCEE los casos de vulneración de derechos fundamentales cuando no sea posible obtener una solución mediante una investigación ordinaria del Defensor del Pueblo" (la traducción es de la autora).

28 Contribución de J.Söderman, Defensor del Pueblo Europeo, sobre Propuestas de modificaciones del Tratado, CONV 221/02, Bruselas, 26 de julio de 2002 (CONTRIB 76), pág. 3. 
Pueblo, el Tratado Constitucional consagraba el derecho a una buena administración (art. II-101).

Por lo demás, la Constitución Europea mantenía básicamente la redacción originaria del Tratado de Maastrich en cuanto a su elección, duración de su mandato, independencia, ámbito de competencias y procedimiento básico de actuación, remitiendo al Parlamento la regulación de su Estatuto, previo dictamen de la Comisión y previa aprobación del Consejo (art. III-335).

Por último, el Tratado de Lisboa de 13 de diciembre de 2007, que entró en vigor el 1 de diciembre de 2009, no incorpora ninguna novedad al respecto y reproduce esencialmente la regulación mencionada en el nuevo artículo 6 del Tratado de la Unión Europea (TUE) —que hace una remisión genérica a la Carta de los Derechos Fundamentales de 7 de diciembre de $2000^{29}$ - y en el artículo 228 del Tratado de Funcionamiento de la Unión Europea (TFUE).

\section{EL ESTATUTO DEL DEFENSOR DEL PUEBLO EUROPEO}

\section{III.1. El estatuto Personal del Defensor del Pueblo}

\section{A) Elección}

El Defensor del Pueblo Europeo es elegido por el Parlamento Europeo para toda la Legislatura por la mayoría de los votos emitidos mediante votación secreta, y su mandato es renovable (art. 228.2 TFUE y art. 204 RPE) ${ }^{30}$.

Conforme a lo dispuesto en el artículo 204 del Reglamento del Parlamento Europeo, al principio de cada Legislatura, inmediatamente después de la elección del Parlamento, o en los casos de cese del Defensor del Pueblo por renuncia, fallecimiento, o destitución, el Presidente de la Cámara convocará la presentación de candidaturas con vistas al nombramiento del Defensor del Pueblo, fijando el plazo para la presentación de las mismas. Dicha convocatoria se publicará en el Diario Oficial de la Unión Europea.

Las candidaturas habrán de contar con el apoyo de 40 diputados como mínimo, que sean nacionales de al menos 2 Estados miembros. Cada diputado podrá apoyar únicamente una candidatura. Además, las candidaturas deberán ir acompañadas de todos los justificantes necesarios para establecer con

29 La Carta de los Derechos Fundamentales de la Unión Europea fue solemnemente proclamada por las instituciones comunitarias el 7 de diciembre de 2000 (DOCE C n. ${ }^{\circ} 346$, de 18 de diciembre de 2000) y adaptada al Tratado de Lisboa de 7 de diciembre de 2007 (DOUE C n. ${ }^{\circ} 303$, de 14 de diciembre de 2007) en el cual se incorpora por referencia en el nuevo artículo 6.1 del TUE que dispone: "La Unión reconoce los derechos, libertades y principios enunciados en la Carta de los Derechos Fundamentales de 7 de diciembre de 2000, tal como fue adoptada el 12 de diciembre en Estrasburgo, a cual tendrá el mismo valor jurídico que los Tratados". Así pues, su plena eficacia jurídica está ligada a la entrada en vigor del Tratado de Lisboa.

30 Versión consolidada del Reglamento del Parlamento Europeo de 12 de julio de 2010. 
seguridad que el candidato reúne las condiciones que establece el artículo 6.2 del Estatuto del Defensor del Pueblo ${ }^{31}$, a saber:

a) Tener la ciudadanía de la Unión.

b) Estar en pleno disfrute de sus derechos civiles y políticos.

c) Ofrecer plenas garantías de independencia.

d) Y reunir las condiciones requeridas en su país de origen para el ejercicio de las más altas funciones jurisdiccionales o poseer experiencia y competencia notorias para el ejercicio de las funciones del Defensor del Pueblo.

Las candidaturas se trasladan a la Comisión competente — esto es, la Comisión de Peticiones ${ }^{32}$ - que puede solicitar oír a los interesados. Estas audiencias están abiertas a todos los diputados ${ }^{33}$.

Las candidaturas admitidas a trámite se someterán a votación por orden alfabético. Antes de proceder a la votación, el Presidente comprobará que hay quórum (en este caso, la presencia de la mitad como mínimo de los diputados que integran la Cámara).

Si al finalizar las dos primeras votaciones no resulta elegido ningún candidato, únicamente podrán mantenerse los dos candidatos que hubieren obtenido el mayor número de votos en la segunda votación. En todos los casos de empate de votos, se considerará vencedor el candidato de más edad.

31 Decisión del Parlamento Europeo sobre el Estatuto del Defensor del Pueblo y sobre las condiciones generales del ejercicio de sus funciones, aprobada por el Parlamento Europeo el 9 de marzo de 1994 (DO L 113, de 4 de mayo de 1994) y modificada por las Decisiones de 14 de marzo de 2002 (DO L 92, de 9 de abril de 2002) y de 18 de junio de 2008 (DO L 189, de 17 de julio de 2008).

32 En virtud de lo dispuesto en la Disposición XX.2 del Anexo VII del Reglamento del Parlamento Europeo, la Comisión competente para las relaciones con el Defensor del Pueblo Europeo es la Comisión de Peticiones.

33 En las cinco elecciones que habido del Defensor del Pueblo Europeo (1995,1999, 2002, 2004 y 2010) se han celebrado estas audiencias ante la Comisión de Peticiones del Parlamento Europeo. Por lo general, la audiencia a cada uno de los candidatos no ha sobrepasado la hora de duración. En ese tiempo, los primeros diez minutos se han dedicado a escuchar la presentación que hace cada candidato - en la que expone las razones de su candidatura, su experiencia en otros cargos similares a nivel nacional, los apoyos con los que cuenta, etc.- y el resto del tiempo a preguntas de los parlamentarios. A título ilustrativo, véanse las audiencias al candidato español Álvaro Gil-Robles (exDefensor del Pueblo del Reino de España) el 29 de junio de 1995 (Info Memo Spécial n. ${ }^{\circ}$ 13/def, Audition des candidats à la nomination au poste de premier médiateur européen, Bruselas, 30 de junio de 1995) y al candidato español Xabier Markiegi (exDefensor del Pueblo del País Vasco) el 26 de noviembre de 2002 (Comisión de Peticiones del PE, DV/476198ES.doc, PE322.920, Bruselas, 26 de noviembre de 2002). Asimismo, pueden consultarse las elecciones del Defensor del Pueblo, celebradas en 2002; http://www.europarl.europa.eu/comparl/peti/election2002/default_es.htm; 2004 http://www.europarl.europa.eu/comparl/peti/election2004/default_en.htm y 2009 en http://www.europarl.europa.eu/electionombudsman/es/ 
La elección del primer Defensor del Pueblo se produjo en la sesión plenaria del Parlamento Europeo de 12 de julio de $1995^{34}$.

Una vez nombrado, el candidato prestará juramento o promesa ante el Tribunal de Justicia de la Unión Europea, asumiendo el compromiso solemne de ejercer sus funciones con independencia e imparcialidad absolutas y de respetar, durante su mandato y tras el cese de sus funciones, las obligaciones que derivan del cargo y, en particular, los deberes de honestidad y discreción en cuanto a la aceptación, una vez terminado su mandato, de determinadas funciones o beneficios (art. 204.7 RPE y art. 9.2 EDP).

\section{B) Cese}

En general, el mandato del Defensor del Pueblo se extingue con el fin de la Legislatura del Parlamento Europeo (art. 228.2 TFUE) con lo que, curiosamente, al coincidir ambos mandatos, el Defensor del Pueblo parece convertirse en el Defensor del Pueblo "de un Parlamento" —el que lo ha elegido- y no "del Parlamento ${ }^{35}$. A mi juicio, hubiera sido deseable deslindar los dos mandatos, evitando así la posible o hipotética presión de los grupos políticos mayoritarios sobre el Defensor del Pueblo.

No obstante, es posible que el mandato del Defensor del Pueblo concluya anticipadamente por renuncia voluntaria ${ }^{36}$, fallecimiento o destitución.

En este último caso, el Tratado y el Reglamento del Parlamento Europeo prevén que una décima parte de los diputados del Parlamento Europeo podrá solicitar la destitución del Defensor del Pueblo si éste deja de cumplir las condiciones necesarias para el ejercicio de sus funciones o comete una falta grave (art. 228.2 TFUE y art. 206.1 RPE).

Esta solicitud será transmitida al Defensor del Pueblo y a la Comisión de Peticiones, la cual, si considera por la mayoría de sus miembros que los motivos invocados son fundados, presentará un informe al Parlamento. El Reglamento de la Cámara prevé que el Defensor del Pueblo pueda ejercer su derecho a la defensa ante dicha Comisión, antes de que ésta proceda a la votación del citado informe (art. 206.2). Posteriormente, el Parlamento, después de debatir el informe, decidirá por votación secreta.

34 Decisión 95/376/CE/EURATOM/CECA del Parlamento Europeo, de 12 de julio de 1995, por la que se nombra a J. Söderman Defensor del Pueblo Europeo (DO L 225, de 22 de septiembre de 1995). Sobre esta primera elección de 1995, véase CARMONA Y CHOUSSAT, J.F.: El Defensor del Pueblo Europeo, INAP, Madrid 2000, pág. 150 y ss. Jacob Söderman fue reelegido para la Legislatura 1999/2004, si bien renunció por razones personales en 2002. En 2003 fue elegido Nikiforos Diamandouros, que anteriormente fue Defensor del Pueblo de Grecia, y que fue reelegido en 2004, y nuevamente el 20 de enero de 2010 por 340 votos.

35 HOYO RODRIGO, J.: "El Defensor del Pueblo Europeo", en la obra colectiva dirigida por E. ÁLVAREZ CONDE y V. GARRIDO Comentarios a la Constitución Europea, Libro I, Tirant Lo Blanch, Valencia 2004, pág. 1.309.

36 El Defensor Jacob Söderman, reelegido por el Parlamento Europeo para la Legislatura 1999/2004 renunció voluntariamente al cargo en 2002. 
En el caso de que el Parlamento se pronuncie favorablemente a la destitución del Defensor del Pueblo, y en el caso de que éste no actuare en consecuencia — o dicho de otra forma, no dimitiera — el Presidente de la Cámara pedirá al Tribunal de Justicia, a más tardar en el período parcial de sesiones siguiente al de la votación, que destituya al Defensor del Pueblo, rogándole que se pronuncie rápidamente. La renuncia voluntaria del Defensor del Pueblo pondrá fin al procedimiento (art. 206. 4 RPE).

Se trata, pues, de una competencia compartida entre el Parlamento Europeo y el Tribunal de Justicia de la Unión, ya que será este órgano jurisdiccional el que decida si procede o no la destitución. Podría pensarse que debería ser el Parlamento Europeo — que elige al Defensor del Pueblo- el órgano que decidiera en exclusiva sobre su cese. Sin embargo, en mi opinión, que sea precisamente un órgano independiente e imparcial como el Tribunal de Justicia - ante el que jura su cargo el Defensor- el que decida finalmente sobre su destitución es una garantía más de la independencia real de este último.

De todas formas, resulta extraño que ni el Estatuto del Defensor del Pueblo, ni el Estatuto del Tribunal de Justicia de la Unión Europea, ni su Reglamento de Procedimiento hayan contemplado el trámite de audiencia al Defensor del Pueblo durante las actuaciones que se practiquen ante el Tribunal de Justicia para proceder a su destitución, ya que de esa omisión podría resultar una clara indefensión de aquél.

Por otro lado, salvo en el supuesto de destitución y evidentemente en caso de fallecimiento, el Defensor del Pueblo seguirá en funciones hasta la toma de posesión del nuevo Defensor del Pueblo, lo cual es totalmente consecuente con la idea de evitar un "vacío de poder" en la defensa de los derechos de los ciudadanos.

Pues bien, cuando se produzca el cese anticipado en sus funciones, se nombrará un nuevo Defensor del Pueblo en un plazo de tres meses contado a partir del momento en que se produzca la vacante, pero únicamente hasta el término de la Legislatura (art. 7 EDP) ${ }^{37}$.

Por último, creo necesario subrayar que la existencia de una clara rivalidad inicial — por razones competenciales- entre la Comisión de Peticiones del Parlamento Europeo y la creación de la figura del Defensor del Pueblo Europeo aún no ha provocado en este ámbito del procedimiento de elección y cese del Defensor, ningún tipo de tensión, ya que en relación con su elección, el papel de la Comisión de Peticiones se reduce únicamente a dar audiencia a los candidatos; y en su cese, a presentar, previa audiencia al Defensor, un informe al Parlamento sobre si considera fundados los motivos invocados para proceder a la destitución

37 Cuando en 2002 renunció al cargo J. Söderman, se eligió un nuevo Defensor del Pueblo, Nikoforos Diamandouros, cuyo mandato duró hasta el final de la Legislatura en 2004. Fue reelegido para la legislatura 2004/2009. 


\section{C) Independencia y prerrogativas}

El Defensor del Pueblo ejercerá sus funciones con total independencia, atendiendo al interés general de la Unión y de sus ciudadanos. En tal sentido, en el desempeño de sus funciones no solicitará ni admitirá instrucciones de ninguna institución, órgano u organismo. Asimismo, durante su mandato, el Defensor del Pueblo no podrá desempeñar ninguna función política o administrativa, ni actividad profesional alguna, sea remunerada o no (art. 228.3 TFUE y arts. 9.1 y 10.1 EDP).

Al Defensor del Pueblo le son de aplicación los artículos 11 a 14 y 17 del Protocolo sobre los privilegios e inmunidades de la Unión Europea ${ }^{38}$.

En lo que se refiere a la remuneración, complementos salariales y pensión de jubilación, el Defensor del Pueblo está equiparado a un Juez del Tribunal de Justicia de la Unión Europea (art. 10.2 EDP).

Por otra parte, parece claro que el Defensor del Pueblo difícilmente podría desempeñar sus funciones con total independencia si no cuenta con los necesarios y suficientes medios materiales y humanos. En este sentido, el Estatuto del Defensor del Pueblo prevé que el Defensor estará asistido por una Secretaría, cuyo principal responsable será nombrado por él mismo (art. 11).

Los funcionarios y agentes de esta Secretaría — cuyo número se adopta cada año en el marco del procedimiento presupuestario ${ }^{39}$ — están sujetos a los reglamentos y normativas aplicables a los funcionarios y otros agentes de la Unión Europea, y les son de aplicación los mismos privilegios e inmunidades que al Defensor del Pueblo.

Esta Secretaría se configura como una unidad administrativa autónoma, y para todas las cuestiones relativas a su personal, el Defensor del Pueblo está asimilado a las instituciones en el sentido del artículo 1 del Estatuto de los funcionarios de las Comunidades Europeas ${ }^{40}$ (art. 11.4 EDP). En 2008 se llevó a

38 Entre ellos, destacan: a) la inmunidad de jurisdicción respecto de los actos por ellos realizados con carácter oficial, sin perjuicio de las disposiciones de los Tratados relativas, por una parte, a las normas sobre responsabilidad de los funcionarios y agentes de la Unión, y por otra, a la competencia del Tribunal de Justicia para conocer de los litigios entre la Unión y sus funcionarios y agentes; b) exención de los impuestos nacionales sobre los sueldos, salarios y emolumentos abonados por la Unión; c) régimen especial de prestaciones sociales. No obstante, hay que señalar que el artículo 17 del citado Protocolo dispone que "cada Institución de la Unión estará obligada a suspender la inmunidad concedida a un funcionario u otro agente en los casos en que estime que esta suspensión no es contraria a los intereses de la Unión".

39 En el Presupuesto general de la UE (Anexo de la Sección 1, Parlamento Europeo) de 1995 se previeron 10 puestos para la Secretaría del Defensor del Pueblo. En 2008, el número de puestos de la plantilla del Defensor del Pueblo era de 57, el mismo que en 2006. Por otra parte, el total del crédito presupuestado para 2008 ascendió a 8.505.770 €. En 2009, el crédito presupuestado fue de $8.906 .880 €$ y en 2010 , de $9.332 .275 €$. En la actualidad, el número de puestos es de 63 gracias a que la autoridad presupuestaria autorizó un aumento de seis puestos de trabajo en el presupuesto de 2009.

40 Reglamento n. 31 (CEE) 11 (CEEA) por el que se establece el Estatuto de los funcionarios y el régimen aplicable a los otros agentes de la Comunidad Europea y de la CE de la Energía Atómica (DO P 45, de 14 de junio de 1962), modificado por última vez por el Reglamento $n .^{\circ}$ $337 / 2007$ del Consejo, de 27 de marzo de 2007 (DO L 90, de 30 de marzo de 2007). 
cabo un ambicioso programa de reestructuración interna, que entró en vigor el 1 de julio. La reestructuración supuso la creación de cuatro Unidades en cada uno de los dos Departamentos existentes: el Departamento Jurídico y el Departamento de Administración y Finanzas. Con ello se consiguió una estructura basada en dos Jefes de Departamento, correspondientes al rango de directores y que dependen del Secretario General, ambos asistidos por cuatro Jefes de Unidad con mayores facultades de gestión. sonal.

Esta reorganización interna se puso en marcha sin contratar nuevo per-

Por último, y según lo dispuesto en el artículo 13 del Estatuto del Defensor del Pueblo, la sede del Defensor del Pueblo es la del Parlamento Europeo. En este sentido, hay que señalar que los redactores del Estatuto no valoraron suficientemente el hecho de que las sedes de la Eurocámara estén dispersas entre Estrasburgo, Bruselas y Luxemburgo. Lo cierto es que aunque se mantiene una pequeña oficina en Bruselas, el Defensor del Pueblo y la mayor parte del personal de su Secretaría se encuentran en Estrasburgo.

\section{III.2. Acceso al Defensor del Pueblo Europeo: aDmisibilidad de las RECLAMACIONES}

El Defensor del Pueblo Europeo está facultado para recibir las reclamaciones de cualquier ciudadano de la Unión o de cualquier persona física o jurídica que resida o tenga su domicilio social en un Estado miembro relativas a casos de mala administración en la acción de las instituciones, órganos u organismos de la Unión, con exclusión del Tribunal de Justicia de la Unión Europea, en el ejercicio de sus funciones jurisdiccionales (art. 228.1 TFUE). En idéntico sentido se recoge en el artículo 43 de la Carta de los Derechos Fundamentales de la Unión Europea.

Esta limitación impuesta por el Tratado y por la Carta, en virtud de la cual se restringe el acceso al Defensor del Pueblo exclusivamente a los ciudadanos europeos y a las personas físicas o jurídicas que residan legalmente o tengan su sede social en un Estado miembro de la Unión, choca frontalmente con uno de los rasgos más significativos de la identidad de esta figura: que pueda dirigirse a él toda persona natural o jurídica, sin que pueda constituir un impedimento la nacionalidad o la residencia ${ }^{41}$.

La solución en la práctica viene dada por el hecho de que el Tratado permite al Defensor del Pueblo actuar por iniciativa propia (art. 228.1 TFUE) con lo cual, en el caso de que la reclamación fuera presentada por una persona a la que el Tratado no reconozca legitimación activa - porque no resida o tenga su domicilio social en un Estado miembro de la Unión Europea- el De-

41 En este sentido, véase el artículo 10.1 de la Ley Orgánica 3/1981, de 6 de abril, del Defensor del Pueblo. 
fensor del Pueblo puede iniciar la tramitación del caso de oficio, siempre que considere necesaria la tutela del derecho presuntamente vulnerado ${ }^{42}$.

El Tratado también prevé que la reclamación pueda dirigirse indirectamente al Defensor del Pueblo a través de un miembro del Parlamento Europeo. Pero esta intermediación, característica del Parliamentary Commissionner británico, es sólo complementaria de la reclamación directa, y no responde realmente a las necesidades de los ciudadanos, que normalmente prefieren un acceso directo ${ }^{43}$, por lo que hubiera resultado más idóneo preservar la inmediatez de trato entre el Defensor y el reclamante. Las razones son claras: la iniciación indirecta del procedimiento ante el Defensor del Pueblo podría suponer la instrumentalización política por parte de los diputados europeos de la figura del Defensor del Pueblo, así como el control funcional puntual sobre sus prioridades de intervención. Y además, como señaló en su día Moreira González, el Parlamento Europeo podría desviar las quejas dirigidas al Defensor del Pueblo y orientarlas hacia la Comisión de Peticiones, aumentando así su protagonismo e impidiendo a aquél intervenir ${ }^{44}$.

Además, teniendo en cuenta que ni el Tratado ni el Estatuto del Defensor del Pueblo hacen una definición uniforme de "persona residente o domiciliada en la Unión" y, en consecuencia, depende de la regulación que haga cada Estado miembro en su ordenamiento jurídico interno, a lo que se une el hecho de que el Reglamento del Parlamento Europeo no exige el requisito de la ciudadanía europea ni de la residencia en un Estado miembro de la Unión para dirigir una petición al Parlamento, es evidente que se potencia el protagonismo institucional de éste frente a las personas de terceros Estados que pudieran ver lesionados sus derechos por la administración comunitaria.

No parece que la solución articulada por la Decisión del Defensor del Pueblo por la que se adoptan disposiciones de aplicación, en el sentido de que «toda petición trasladada al Defensor del Pueblo por el Parlamento Europeo, con el consentimiento del peticionario, será tratada como una reclamación ${ }^{45}$ sea la adecuada para evitar posibles bloqueos en la actuación del Defensor Europeo por parte de la Comisión de Peticiones ${ }^{46}$.

Por lo que se refiere a la posibilidad de presentar reclamaciones colectivas, nada dicen el Tratado ni el Estatuto del Defensor del Pueblo. Por eso, y

42 En este sentido, entre otros, Pierucci, A.: "Les recours au Médiateur Européen", en E.A. MARIAS (ed.) European Citizenship, European Institute of Public Administation, Maatricht, 1994, pág. 103-115

43 Resulta muy interesante al respecto la posición crítica sobre la posible adopción por el TUE del sistema británico de D.C. ROWA en su artículo "Pourquoi un Ombudsman parlementaire?", en Révue Française d'Administration Publique n. ${ }^{\circ}$ 64, 1992, pág. 567-574.

44 MOREIRA GONZÁLEZ, C.J.: «El Defensor del Pueblo en el Tratado de la Unión Europea”, cit. pág. 232. En idéntico sentido, RUIZ FRANCÉS, Á.: “El Defensor del Pueblo de la Unión Europea", cit., pág. 99.

45 Artículo 2.3 de la Decisión del Defensor del Pueblo por la que se adoptan disposiciones de aplicación, cit.

46 Véase STEENBJERG KOLZE, N.: Le Médiateur Européen, CEDRE, Rennes, 1995, pág. 16 y ss. 
teniendo en cuenta que el Reglamento del Parlamento Europeo, al regular el derecho de petición ${ }^{47}$, dispone que podrá ser ejercido "individualmente o asociado con otros ciudadanos o personas", podríamos concluir que también es posible que una reclamación sea presentada de forma colectiva.

Por otra parte, y en cuanto al procedimiento a seguir en la presentación de una reclamación ante el Defensor del Pueblo Europeo, hay que destacar que no se regula un procedimiento especialmente formal; antes bien, el procedimiento es extraordinariamente flexible y además, gratuito. En tal sentido, las reclamaciones pueden formularse por escrito, por medio de una carta dirigida al Defensor del Pueblo, utilizando un formulario estándar que facilita la Secretaría del Defensor del Pueblo (disponible en su página web) y en cualquiera de las 23 lenguas reconocidas por el Tratado ${ }^{48}$. Además, en virtud del Acuerdo administrativo entre el Reino de España y el Defensor del Pueblo Europeo de 2006, los ciudadanos españoles o cualquier otra persona física o jurídica que resida o tenga su sede social en España tendrán el derecho de dirigir sus reclamaciones escritas al Defensor del Pueblo Europeo en cualquiera de las lenguas que, conforme al ordenamiento constitucional español, tienen estatuto de lenguas oficiales en el territorio español ${ }^{49}$.

Las reclamaciones pueden presentarse por correo postal, fax o correo electrónico ${ }^{50}$. Eso sí, en la reclamación debe quedar patente el objeto de la misma así como la persona de la que proceda, si bien ésta puede pedir que su reclamación sea confidencial (arts. 2.3 EDP). Asimismo, el Defensor del Pueblo podrá, por iniciativa propia, clasificar como confidencial una reclamación si lo considera necesario para proteger los derechos del demandante o de un tercero (art. 10.1 DDP).

La reclamación debe presentarse en un plazo de dos años, contados desde que el promotor de la misma tuvo conocimiento de los hechos que la motivaron (art. 2.4 EDP).

La aplicación estricta de esta disposición estatutaria resulta más que discutible — por no decir inoperante- si tenemos en cuenta que en la mayoría

47 Sobre el derecho de petición ante el Parlamento Europeo, véase MARIAS, E.A.: "The right to petition the European Parliament after Maastricht", en European Law Revue n. ${ }^{\circ}$ 19, 1994, pág. 169 y ss.

48 Actualmente, con 27 Estados miembros, existen 23 lenguas reconocidas: alemán, búlgaro, checo, danés, eslovaco, esloveno, español, holandés, inglés, estonio, finlandés, francés, griego, húngaro, irlandés (gaélico), italiano, letón, lituano, maltés, polaco, portugués, rumano y sueco.

49 Este Acuerdo administrativo fue firmado de conformidad con las Conclusiones adoptadas por el Consejo de Asuntos Generales y Relaciones Exteriores de la Unión Europea celebrado el 13 de junio de 2005, relativas al uso oficial de otras lenguas en el Consejo y, en su caso, en otros órganos e instituciones de la Unión Europea. En el Acuerdo se prevé un procedimiento especial referido a las traducciones de las comunicaciones- cuando la lengua empleada no sea el español/castellano.

50 La información sobre la forma y requisitos de presentación de una reclamación aparece en una Guía para los Ciudadanos elaborada por el Defensor del Pueblo Europeo y publicada bajo el título ¿Cómo puede ayudarle el Defensor del Pueblo Europeo?, OPCE, Luxemburgo, 2002, pág. 9 Y en su página web http://www.ombudsman.europa.eu/home 
de los sistemas nacionales se puede hacer caso omiso de los plazos cuando sea necesario en interés de la justicia, y que el propio Defensor del Pueblo puede asumir de oficio una reclamación a la que afecte esta dificultad formal para ser tramitada directamente.

Además, que el Estatuto del Defensor del Pueblo exija que previamente se hayan hecho las gestiones administrativas adecuadas ante las instituciones, órganos u organismos de que se trate (art. 2.4 EDP) es un requisito que ha sido interpretado de forma absolutamente flexible por el propio Defensor del Pueblo Europeo al considerar que bastaría con que el reclamante se hubiera puesto en contacto con la institución u órgano interesado, "por ejemplo, por carta o por teléfono, ${ }^{51}$.

Por otra parte, y a pesar de que algunas enmiendas al Proyecto del Informe Bindi sobre el Estatuto del Defensor del Pueblo sugerían que "resultaría muy oportuno requerir un interés legítimo" para presentar una reclamación ${ }^{52}$, lo cierto es que la redacción genérica del Tratado evitó incluir en el Estatuto del Defensor del Pueblo dicha exigencia. Por lo tanto, no es necesario que el reclamante demuestre que se ha visto directamente afectado por el presunto caso de mala administración.

Ahora bien, no debe olvidarse que la presentación de una reclamación no interrumpe los plazos de los recursos fijados en los procedimientos jurisdiccionales o administrativos (art. 2.6 EDP).

Por disposición del Tratado, el Defensor del Pueblo examina las reclamaciones presentadas contra las instituciones, organismos y órganos de la Unión, esto es, contra la Comisión Europea, el Consejo, el Consejo Europeo, el Parlamento Europeo, el Tribunal de Cuentas, el Tribunal de Justicia de la Unión Europea (excepto en el ejercicio de sus funciones jurisdiccionales), el Banco Central Europeo, el Comité Económico y Social, el Comité de las Regiones, el Banco Europeo de Inversiones, EUROPOL ${ }^{53}$, y cualquier otro órgano comunitario ${ }^{54}$.

51 Informe Anual del Defensor del Pueblo Europeo, 1995, pág. 11.

52 Doc. PE 156.133/Enm. 1-19, de 4 de marzo de 1992, pág. 2. Véase también el Informe final de la Comisión de Asuntos Institucionales sobre el Estatuto del Defensor del Pueblo y sobre las condiciones de ejercicio de sus funciones (Ponente: Sra. Bindi), A3-0298/92, de 14 de octubre de 1992 (Doc. PE 200.78/def).

53 En abril de 1999, el Defensor del Pueblo inició una investigación sobre la normativa de EUROPOL en materia de acceso de documentos. Durante el curso de la misma, el Defensor informó, mediante un comunicado de prensa (n. ${ }^{\circ} 11 / 99$, de 28 de septiembre de 1999) que "EUROPOL fue introducido en el mandato del Defensor del Pueblo Europeo por el artículo 41 del TUE, tras ser modificado por el Tratado de Ámsterdam". Nadie planteó objeciones a dicha competencia, con lo que el Defensor del Pueblo podía investigar a los órganos del Tercer Pilar (Cooperación policial y judicial en materia penal). No ocurre lo mismo con los órganos y materias del Segundo Pilar (Política Exterior y de Seguridad Común).

54 Como Agencias u organismos comunitarios descentralizados. Por ejemplo, la Agencia Europea de Medio Ambiente, el Observatorio Europeo de la Droga y las Toxicomanías, la Agencia Europea para la Salud y la Seguridad en el Trabajo, la Oficina de Armonización del Mercado Interior, el Centro de Traducción de los Órganos de la Unión Europea, etc. 
En este sentido, el propio Defensor del Pueblo en su Informe Anual 1995 al Parlamento Europeo, señaló que además de las Instituciones enumeradas en los Tratados, en los órganos comunitarios "están incluidos todos aquellos establecidos por los Tratados (por ejemplo, el Comité Económico y Social, el Comité de las Regiones, o el Banco Europeo de Inversiones) además del conjunto de órganos creados por la legislación comunitaria (por ejemplo, la Agencia Europea de Medio Ambiente, la Fundación Europea para la formación, la Agencia Europea de Evaluación de los Medicamentos, o el Observatorio Europeo de la Droga y las Toxicomanías), „55. Esta interpretación permitiría incluir, a juicio de algunos autores, a los Comités de la comitología ${ }^{56}$. Pero lo cierto es que el Defensor del Pueblo, hasta la fecha, ha centralizado sus investigaciones, dirigiéndose siempre a la institución u órgano principal que hace la delegación. En este sentido, su actuación ha sido avalada por la jurisprudencia del Tribunal de Justicia ${ }^{57}$.

En todo caso, el Defensor del Pueblo no puede admitir reclamaciones:

a) Contra las autoridades nacionales, regionales o locales de los Estados miembros, incluso cuando éstas se refieran a cuestiones sobre la Unión Europea o el Derecho Comunitario.

b) Contra las actividades de los Tribunales o los Defensores del Pueblo nacionales o regionales, ya que el Defensor del Pueblo Europeo no es un órgano de apelación respecto a las decisiones adoptadas por aquéllos.

c) Contra empresas o particulares.

Asimismo, el Defensor del Pueblo tampoco puede admitir ninguna reclamación relativa a las relaciones laborales entre las instituciones y órganos de la Unión y sus funcionarios u otros agentes sin que previamente el interesado haya agotado las posibilidades de solicitud o reclamación administrativas internas, en particular los procedimientos contemplados en los apartados $1 \mathrm{y}$ 2 del artículo 90 del Estatuto de los funcionarios de la U.E., y después de que hayan expirado los plazos de respuesta a la autoridad ante la que se hubiere recurrido (art. $2.8 \mathrm{EDP}$ ).

Igualmente, cuando a causa de un procedimiento jurisdiccional en curso o ya concluido sobre los hechos alegados, el Defensor del Pueblo deba declarar inadmisible una reclamación o dar por terminado el estudio de la misma, se archivarán los resultados de las investigaciones llevadas a cabo hasta ese momento (art. 2.7 EDP). Igualmente, cuando una reclamación no entre en

55 Informe Anual del Defensor del Pueblo Europeo, 1995, pág. 10

56 En tal sentido, HEEDE, K.: European Ombudsman: redress and control at Union level, European Mongraphs n. ${ }^{2}$ 24, Kluwer, La Haya, 2000, pág. 121.

57 En la sentencia del caso Rothmans versus Comisión, de 19 de julio de 1999, el Tribunal de Primera Instancia consideró que los documentos de carácter administrativo de los Comités de la Comitología, son esencialmente documentos de la Comisión (T-188/97, Réc. 1999, pág. II-2463). 
el ámbito de competencia del Defensor del Pueblo Europeo o no pueda ser admitida a trámite, el Defensor del Pueblo dará por concluido el asunto correspondiente e informará al denunciante de su decisión, exponiendo sus motivos (art. 3.2 DDP).

Una vez recibida la reclamación ${ }^{58}$, el Defensor del Pueblo deberá informar de la reclamación a la institución, órgano u organismo interesado, así como acusar recibo de la reclamación, lo cual suele hacer en el plazo de una semana. A continuación, el Defensor del Pueblo —basándose en los criterios enunciados en el Tratado y en su Estatuto- procede a examinar la reclamación, decidiendo sobre su admisibilidad (normalmente en el plazo de un mes) de lo cual informará sin demora al reclamante, así como del desarrollo de su investigación (art. 228.1 TFUE y 2.9 EDP). No obstante, antes de adoptar la decisión sobre la admisibilidad de la reclamación, podrá pedir al demandante que aporte informaciones o documentos complementarios (art. 3.1 DDP).

En comparación con los Defensores del Pueblo nacionales, el Defensor Europeo recibe un número excepcionalmente alto de reclamaciones inadmisibles: en 1995, casi un 80\%; en 2007, el 83\%, y en 2008, el $80 \%$.

Pero hay que subrayar que esto no se debe a que los criterios de admisibilidad sean interpretados bajo un prisma estrictamente legalista o excesivamente técnico. Antes al contrario, dichos criterios son siempre interpretados a favor de los derechos del ciudadano europeo; e incluso, en caso de duda sobre la admisibilidad de una reclamación, el Defensor decide siempre a favor del reclamante. La razón es clara: «si una reclamación es inadmitida bajo un criterio erróneo, son los derechos de los ciudadanos los que se ven perjudicados. Sin embargo, las consecuencias de un error eventual en sentido contrario son mucho menos graves, ${ }^{59}$.

La mayoría de las reclamaciones declaradas inadmisibles están referidas a casos de mala administración en el seno de los Estados miembros.

Una vez admitida a trámite, el Defensor del Pueblo podrá, si lo considera necesario, adoptar disposiciones que permitan tratar con prioridad una reclamación (art. 10.2 DDP).

Además, el Defensor del Pueblo puede aconsejar al reclamante que se dirija a otra autoridad competente (art. 2.5 EDP) e incluso podrá, con el acuerdo del denunciante, remitir su reclamación a dicha autoridad, que puede ser europea o nacional (art. 2.5 DDP). En este sentido, el Defensor del Pueblo

58 Como es lógico, el número de reclamaciones presentadas ha ido aumentando conforme el Defensor del Pueblo Europeo ha sido conocido por los ciudadanos europeos. Así, en 1995 sólo se presentaron 298 reclamaciones; en 2000, 1.732; en 2005, alcanzó la cifra más alta hasta la fecha con 3.920; en 2006, 3.830; en 2007, 3.211; en 2008, 3.406; y en 2009, 3.098. Por el origen geográfico de las reclamaciones, España ocupó el primer puesto en 2006, con 775 reclamaciones (19,8\%), y el segundo en 2007, 2008 y 2009, con 351 reclamaciones (10,9\%) $352(10,3 \%)$ y 389 (13,6\%) respectivamente, después de Alemania, con 507 (15,4\%), 546 (16\%) y $413(13,3 \%)$.

Fuente: Informes Anuales del Defensor del Pueblo Europeo (1995, 2000, 2005, 2006,2007 , 2008 y 2009)

59 Informe Anual del Defensor del Pueblo Europeo, 1995, págs. 11 y 12 
suele trasladar con frecuencia el caso a un miembro de la Red Europea de Defensores del Pueblo ${ }^{60} \mathrm{o}$ aconsejarle que se ponga en contacto con un determinado miembro de la Red.

Por último, quisiera remarcar que el Defensor del Pueblo, desde su puesta en funcionamiento, hace ya quince años, ha hecho un esfuerzo permanente por tratar de resolver los problemas que se le plantean. En este sentido, y como ya hemos señalado, ha abogado siempre, a lo largo de sus Informes Anuales desde 1995, por una interpretación no rigorista de los requisitos de admisibilidad de una reclamación, basada en los principios generales de la interpretación más favorable a los derechos del ciudadano.

\section{IV. ÁMBITO DE COMPETENCIA DEL DEFENSOR DEL PUEBLO EUROPEO: LOS CASOS DE "MALA ADMINISTRACIÓN"}

El Defensor del Pueblo procede a todas las investigaciones que considere necesarias (y justificadas) para aclarar todo posible caso de mala administración en la actuación de las Instituciones y órganos comunitarios, bien por iniciativa propia, bien como consecuencia de una reclamación, salvo que los hechos alegados sean o hayan sido objeto de un procedimiento jurisdiccional (art. 228 TFUE y art. 3.1 EDP).

Nada dicen los Tratados vigentes ni el Estatuto del Defensor del Pueblo sobre qué debe entenderse por "mala administración".

No obstante, ya incluso antes de proclamarse en el año 2000 la Carta de los Derechos Fundamentales de la Unión Europea, que reconoce, en su artículo 41 - y gracias a la propuesta del Defensor del Pueblo- el derecho a una buena administración ${ }^{61}$, la jurisprudencia del Tribunal de Justicia de las Comunidades Europeas consagró el principio de buena administración ${ }^{62}$.

A tenor de lo dispuesto en el artículo 41 de la Carta de los Derechos Fundamentales de la Unión Europea, el derecho a una buena administración significa, en primer lugar, que toda persona tiene derecho a que las instituciones y órganos de la Unión traten sus asuntos imparcial y equitativamente, y dentro de un plazo razonable. Además, este derecho incluye en particular: el derecho de toda persona a ser oída antes de que se tome en contra

60 Creada en 1996, la Red incluye a todos los Defensores del Pueblo nacionales y regionales de los Estados miembros de la Unión Europea, así como a los de Noruega e Islandia. También forman parte de la Red las Comisiones de Peticiones de la UE.

61 Sobre el derecho a una buena administración, véase Fuentetaja, J.A.: "El derecho a una buena administración en la Carta de los derechos fundamentales de la Unión Europea", en Revista de Derecho de la Unión Europea n. ${ }^{\circ}$ 15, 2. ${ }^{\circ}$ semestre de 2008, págs. 137-155

62 Véanse, entre otras, la sentencia del TJCE de 31 de marzo de 1992, C-255/90 P.Burban, Rec. 1992, pág. I-2253; sentencias del TPI de 18 de septiembre de 1995, T-167/94, Nölle, Rec. 1995, pág. II-2589; y de 9 de julio de 1999, T-231-97, New Europe Consulting y otros, Rec. 1999, pág. II-2403. 
suya una medida individual que le afecte desfavorablemente; el derecho de toda persona a acceder al expediente que le afecte, dentro del respeto de los intereses legítimos de la confidencialidad y del secreto profesional y comercial; la obligación que incumbe a la Administración de motivar sus decisiones; el derecho a la reparación por parte de la Unión de los daños causados por sus instituciones o sus agentes en el ejercicio de sus funciones, de conformidad con los principios generales comunes a los Derechos de los Estados miembros; y el derecho a dirigirse a las instituciones de la Unión en una de las lenguas de los Tratados y a recibir una contestación en esa misma lengua.

Con anterioridad, el Defensor del Pueblo Europeo, en su primer Informe Anual al Parlamento Europeo en 1995, ya consideró que "hay mala administración cuando una institución u órgano comunitario no actúa de acuerdo con los Tratados o la legislación comunitaria, o cuando no respeta o contraviene los principios de derecho establecidos por el Tribunal de Justicia, o vulnera los derechos fundamentales". Además, «la mala administración puede englobar otras muchas prácticas, especialmente: irregularidades administrativas, omisiones administrativas, abusos de poder, negligencia, procedimientos ilícitos, injusticias, casos de disfuncionamiento o incompetencia, discriminación, retrasos injustificados, y falta de información o negativa a facilitar información ${ }^{63}$. Posteriormente, el Parlamento Europeo solicitó al Defensor del Pueblo Europeo que definiera dicho concepto. La definición propuesta se encuentra en su Informe Anual de 1997 (y que el Parlamento y la Comisión aceptaron), y fue la siguiente: Se produce mala administración cuando un organismo público no obra de conformidad con las normas o principios a que ha de atenerse obligatoriamente". Este concepto - a juicio de Söderman- debe incluir el respeto a los derechos humanos. "No hay duda de que entre las normas y principios que informan la actuación de todo órgano o institución comunitaria, se encuentran los derechos humanos fundamentales recogidos en la Carta de Niza. Desde la óptica del Defensor del Pueblo Europeo, la violación de los derechos de la Carta debe considerarse, por tanto, como mala administración " ${ }^{64}$.

Pues bien, con el objetivo de definir el significado real de buena administración, teniendo en cuenta que la lista anterior no es exhaustiva, el Defensor del Pueblo redactó, después de elaborar un Informe especial al respecto $^{65}$, el Código Europeo de Buena Conducta Administrativa, que fue

63 Informe Anual del Defensor del Pueblo Europeo, 1995, pág. 9.

64 "El Defensor del Pueblo Europeo y la garantía de los derechos de la ciudadanía europea", conferencia de Jacob Söderman, Defensor del Pueblo Europeo, Jornadas sobre el Día de Europa, organizadas por el Sindic de Greuges de Catalunya, con la cooperación de las representaciones de la Comisión Europea y del Parlamento Europeo, Barcelona, 7 de mayo de 2002.

65 Véase el Informe Especial del Defensor del Pueblo Europeo al Parlamento Europeo relativo a su investigación por iniciativa propia sobre la existencia y el acceso público a un Código de buena conducta administrativa en las instituciones y órganos comunitarios (OI/1/98/OV), de 11 de abril de 2000 . 
aprobado por una Resolución del Parlamento Europeo de 6 de septiembre de $2001^{66}$.

Este Código Europeo de Buena Conducta Administrativa está dirigido a las instituciones y órganos de la Unión Europea, y sus contenidos deben ser respetados por esas administraciones y sus funcionarios en sus relaciones con los ciudadanos. En este sentido, el artículo 1 del Código establece que en sus relaciones con el público, las Instituciones y sus funcionarios respetarán los siguientes principios:

- Legitimidad

- Ausencia de discriminación

- Proporcionalidad

- Ausencia de abuso de poder

- Imparcialidad e independencia

- Objetividad

- Respeto a las legítimas expectativas, consistencia y asesoramiento

- Justicia

- Cortesía

- Respuesta por escrito en la lengua del ciudadano

- Acuse de recibo e indicación del funcionario competente

- Obligación de remisión al servicio competente de la Institución

- Derecho a ser oído y a hacer observaciones

- Plazo razonable de adopción de decisiones

- Deber de indicar los motivos de las decisiones

- Indicación de las posibilidades de apelación

- Notificación de la decisión

- Protección de datos

- Facilitar la información requerida por el ciudadano

- Mantenimiento de archivos adecuados

- Acceso público al Código de Buena Conducta Administrativa

Cualquier incumplimiento por parte de una Institución o un funcionario de estos principios podrá ser objeto de una reclamación ante el Defensor del Pueblo Europeo, de conformidad con lo establecido en el artículo 228 TFUE y el Estatuto del Defensor del Pueblo Europeo (art. 26 del Código).

66 DO C 72, de 21 de marzo de 2002. Código de Buena Conducta Administrativa, Oficina de Publicaciones de la CE, Luxemburgo, .última edición 2005. La idea de un Código similar fue inicialmente propuesta en 1998 por un diputado europeo, R. Perry. El Defensor del Pueblo redactó un proyecto de texto, siguiendo una investigación de oficio y presentándolo como un Informe especial al Parlamento (vid. Nota supra). La Resolución del Parlamento Europeo sobre el Código está basada en la propuesta del Defensor del Pueblo, a la que se introdujeron algunos cambios propuestos por R. Perry como Ponente del Informe especial de la Comisión de Peticiones del Parlamento Europeo. El Código tiene en cuenta los principios de Derecho Administrativo europeo contenidos en la jurisprudencia del Tribunal de Justicia de la Unión Europea, y también en los Derechos nacionales. 


\section{IV.1. OTROS DERECHOS FUNDAMENTALES PROTEGIDOS}

Como ya hemos puesto de manifiesto, el Defensor del Pueblo puede investigar los casos de "mala administración" provocados por la vulneración de un derecho fundamental. En este sentido, y sólo a título de ejemplo, voy a señalar algunos de los derechos protegidos por el Defensor a lo largo de estos años.

A) El acceso a los documentos de las Instituciones, órganos y organismos de la Unión

Como es sabido, la transparencia constituye un principio esencial de la democracia, que no siempre es respetado plenamente por las instituciones y órganos comunitarios. En este sentido, y como señaló en su Informe anual de 1995 el entonces Defensor del Pueblo Europeo, Jacob Söderman, "el acceso a la información contribuye de manera importante a la transparencia y es un elemento clave para facilitar la participación colectiva o individual de los ciudadanos en las actividades de la Unión".

La existencia de una administración abierta y responsable se garantiza a través de una serie de medidas y derechos, entre los que destaca el derecho de todo ciudadano de la Unión o toda persona física o jurídica que resida o tenga su domicilio social en un Estado miembro a acceder a los documentos de las Instituciones, órganos y organismos de la Unión ${ }^{67}$, cualquiera que sea su soporte, con arreglo a una serie de principios y condiciones que se establecerán en los correspondientes Reglamentos del Parlamento Europeo y el Consejo (art. 42 de la Carta y artículo 15.3 del TFUE) ${ }^{68}$.

Pues bien, el Defensor del Pueblo ha luchado desde el principio de su puesta en marcha por ampliar en lo posible el acceso a la información proporcionada por las instituciones comunitarias. En este sentido, el Defensor del Pueblo elaboró, en 1997, un Informe especial dirigido al Parlamento Europeo, tras haber realizado una investigación de oficio sobre el acceso del público a los documentos, como consecuencia de haber recibido un elevado número de reclamaciones motivadas por la denegación de algunas instituciones y órganos comunitarios a permitir el acceso a sus documentos ${ }^{69}$.

67 A tenor de lo dispuesto en el artículo 15. 3 del TFUE, el Tribunal de Justicia de la Unión Europea, el Banco Central Europeo y el Banco Europeo de Inversiones sólo estarán sujetos a las obligaciones derivadas de este derecho cuando ejerzan funciones administrativas.

68 Sobre este tema, véase Martín González, Y.: «El Defensor del Pueblo Europeo: garante de los derechos a la información y de acceso a los documentos de la Unión Europea", en Revista de Estudios Europeos n. ${ }^{\circ}$ 43, 2006, pág. 43-54.

69 Informe especial del Defensor del Pueblo al Parlamento Europeo elaborado tras la investigación de oficio sobre el acceso del público a los documentos (616/PUBAC/F/IJH) de 15 de diciembre de 1997. 
En mayo de 2001, el Parlamento Europeo y el Consejo aprobaron un Reglamento relativo al acceso del público a los documentos del Parlamento Europeo, del Consejo y de la Comisión, en virtud del cual estas instituciones deben mantener un registro público de documentos, al que se puede acceder en formato electrónico, y que debe ser permanentemente actualizado ${ }^{70}$.

Por lo que se refiere al acceso del público a los documentos no publicados custodiados por el Defensor del Pueblo Europeo, la Decisión del Defensor del Pueblo Europeo por la que se adoptan disposiciones de aplicación, en su artículo 14, dispone que el público podrá acceder a aquéllos con arreglo a las mismas condiciones y restricciones establecidas por el Reglamento antes citado para el acceso del público a los documentos del Parlamento Europeo, del Consejo y de la Comisión.

Mención aparte merece el derecho del público a solicitar el acceso a documentos relacionados con la investigación del Defensor del Pueblo Europeo, custodiados por éste, siempre que a solicitud del denunciante o del Defensor del Pueblo no se haya clasificado la reclamación como confidencial (art. 14.2 DDP). Además, tampoco se concederá el acceso:

- A los documentos o información obtenida de las instituciones y órganos comunitarios, así como de las autoridades de los Estados miembros, de los que se hubiera especificado claramente por aquéllos que se consideraban reservados (arts. 14.2 y 5.1 y 2 DDP).

- A los testimonios aportados a título confidencial por funcionarios y agentes de las instituciones u órganos de la Unión (arts. 14. 2 y 5.3 DDP).

- A aquellas partes de su informe o réplicas a ulteriores investigaciones que la institución afectada haya solicitado que se divulguen únicamente al denunciante (arts. 14.2 y 5.4 DDP)

- A un documento cuya divulgación pudiera causar perjuicio a la integridad de una investigación en marcha (art. 14.2 DDP).

Las solicitudes de acceso a los documentos custodiados por el Defensor del Pueblo Europeo se presentarán por escrito (por carta, fax o correo electrónico) y de manera suficientemente precisa para permitir la identificación del documento. Se dará acceso in situ o mediante expedición de una copia. La desestimación total y parcial de una solicitud de acceso a un documento deberá ser motivada (art. 14. 3, 4, 5 y 6 DDP).

B) El derecho a la protección de datos de carácter personal

Por otra parte, el concepto de "mala administración" también incluye el no cumplimiento de la legislación comunitaria en materia de protección de datos,

70 Reglamento (CE) 1049/2001, del Parlamento Europeo y del Consejo de 30 de mayo de 2001, relativo al acceso del público a los documentos del Parlamento Europeo, del Consejo y de la Comisión (DO L 145, de 31 de mayo de 2001. 
y en consecuencia, la posible vulneración del derecho fundamental de toda persona a la protección de datos de carácter personal que la conciernan, reconocido en el artículo 8 de la Carta de los Derechos Fundamentales de la Unión Europea.

Para una defensa más eficaz de este derecho, el Defensor del Pueblo Europeo y el Supervisor Europeo de Protección de Datos ${ }^{71}$, acordaron mediante un Memorándum ${ }^{72}$ establecer un sistema de trabajo flexible para evitar una duplicación de procedimientos innecesaria y, en la medida de lo posible, interpretaciones divergentes en tales casos.

El objetivo común del Defensor del Pueblo Europeo y del Supervisor Europeo es conseguir un mejor uso de los recursos comunitarios y favorecer un planteamiento coherente de los aspectos jurídicos y administrativos de la protección de datos, promoviendo con ello los derechos e intereses de los reclamantes y de los ciudadanos en general. Por lo tanto, el Memorándum de Acuerdo no pretende crear derechos ni obligaciones legales, sino una base para una cooperación constructiva entre ambos.

En este sentido, el Defensor del Pueblo Europeo debe informar al reclamante, cuando proceda, de las potestades específicas del Supervisor Europeo de Protección de Datos, y de las condiciones necesarias para presentar reclamaciones ante dicha institución relativas al tratamiento de datos personales por parte de las instituciones y órganos comunitarios. En el mismo sentido, el Supervisor Europeo de Protección de datos se compromete a informar al reclamante, cuando proceda, de que las reclamaciones relativas a la mala administración en las actividades de las instituciones y órganos de la Unión pueden presentarse al Defensor del Pueblo Europeo (art. 2.I.A) MA).

71 El Reglamento (CE) 45/2001 del Parlamento Europeo y del Consejo de 18 de diciembre de 2000, relativa a la protección de las personas físicas en lo que respecta al tratamiento de datos personales y a la libre circulación de estos datos (DO L 8, de 12 de enero de 2001) disponía en su artículo 24.1 que "cada Institución y órgano comunitario designará al menos una persona como responsable de la protección de datos". En este marco se encuadra la Decisión del Defensor del Pueblo Europeo por las que se adoptan las normas de desarrollo relativas a las tareas, competencias y obligaciones del Responsable de la protección de datos, de 3 de septiembre de 2002

Asimismo, el citado Reglamento creaba, en su artículo 41, la figura del Supervisor Europeo de Protección de Datos como una autoridad de control independiente, nombrada de común acuerdo por el Parlamento Europeo y el Consejo por un período de 5 años, sobre la base de una lista establecida por la Comisión, después de abrir un plazo para la presenación de candidaturas.

De acuerdo con lo establecido en el artículo 43.1 del Reglamento 45/2001, el estatuto y las condiciones generales de desempeño de las funciones del Supervisor Europeo de Protección de Datos fueron fijados de común acuerdo mediante la Decisión n. ${ }^{\circ}$ 1247/2002/CE del Parlamento Europeo, del Consejo y de la Comisión, de 1 de julio de 2002 (DO L 183, de 12 de julio de 2002). El primer Supervisor Europeo de Protección de Datos fue nombrado mediante una Decisión del Parlamento Europeo y del Consejo de 22 de noviembre de 2003(DO L 12, de 17 de enero de 2004).

72 Memorándum de Acuerdo entre el Defensor del Pueblo Europeo y el Supervisor Europeo de Protección de Datos de 30 de noviembre de 2006 (2007/C 27/07) DO C 27, de 7 de febrero de 2007. 
El Memorándum no se pronuncia respecto a las competencias del Defensor del Pueblo Europeo y del Supervisor Europeo de Protección de Datos de investigarse mutuamente.

C) El derecho a la libertad de expresión de los funcionarios de la Unión Europea

El Defensor del Pueblo Europeo también ha velado por los derechos del personal de las instituciones. En este sentido, la labor del Defensor del Pueblo consiguió la modificación del Estatuto de los Funcionarios comunitarios, cuyo originario artículo 17 exigía autorización previa para toda publicación que guarde relación con la actividad de las Comunidades.

Al no existir criterios interpretativos de esta norma, y considerando que una interpretación en sentido amplio podría desvirtuar, e incluso vulnerar, el derecho de los funcionarios a la libertad de expresión, el Defensor del Pueblo se dirigió a la Comisión en 1997 y en 200073, advirtiendo de la necesidad de establecer guías de actuación que delimitaran más claramente el marco de aplicación de los citados artículos del Estatuto de los Funcionarios, y a que estableciera orientaciones a sus funcionarios sobre cómo hallar el equilibrio justo entre su derecho a la libertad de expresión y sus deberes como funcionarios.

Con la firma en el año 2000 de la Carta de los Derechos Fundamentales de la Unión Europea, en cuyo artículo 11 se reconoce el derecho de toda persona a la libertad de expresión, el Defensor del Pueblo Europeo realizó en 2001 una investigación de oficio sobre la libertad de expresión de los funcionarios comunitarios, al considerar que los derechos y obligaciones de los funcionarios no estaban bien delimitados ${ }^{74}$. En esta investigación solicitó al Presidente de la Comisión información detallada sobre las iniciativas que iba a tomar la Comisión para garantizar el ejercicio de dicho derecho.

Según el entonces Defensor del Pueblo Europeo, J. Söderman, «los funcionarios no parecían disponer de ninguna indicación clara para saber dónde acababa el contacto abierto y útil con los ciudadanos y dónde empezaban las declaraciones que pudieran "atentar a la dignidad de su función", según establece su Estatuto. Desgraciadamente, era previsible que semejante situación truncara el objetivo de las Comunidades de alcanzar los parámetros de apertura y transparencia deseables y necesarios."

Las dos principales medidas que la Comisión propuso fueron las siguientes:

73 Decisión del Defensor del Pueblo Europeo en el asunto 794/96/EAW/SW/VK, de 13 de octubre de 1997; y Decisión en el asunto 1219/99/ME, de 18 de diciembre de 2000.

74 Investigación de oficio del Defensor del Pueblo Europeo sobre la libertad de expresión de los funcionarios: Decisión del Defensor del Pueblo Europeo en el asunto OI/2001/GG, de 9 de enero de 2002 . 
- Una guía administrativa para explicar la aplicación e interpretación de las normas del Estatuto de los funcionarios y otros agentes. La primera parte de esta guía debería facilitarse al personal de la Comisión en los primeros meses de 2002.

- Modificaciones concretas del Artículo 17 del Estatuto, por el que se establece el deber de los funcionarios de obtener autorización previa para publicar cualquier texto cuyo objeto tenga relación con la actividad de las Comunidades. Según la Comisión, su propuesta definía mejor los criterios que puede adoptar la autoridad facultada para proceder a los nombramientos para denegar dicho permiso.

Este compromiso de la Comisión para modificar el Estatuto de los funcionarios en el sentido propuesto por el Defensor del Pueblo Europeo se produjo finalmente en $2003^{75}$ con la incorporación de un artículo 17 bis, en el que se reconoce el derecho de todo funcionario a la libertad de expresión, "en el debido respeto de los principios de lealtad e imparcialidad". Además, cuando un funcionario se proponga publicar, individualmente o en colaboración, cualquier escrito que se refiera a la actividad de las Comunidades, el apartado 2 del artículo 17 bis dispone que el aquél deberá notificárselo previamente a la autoridad facultada para proceder a los nombramientos. Si esta autoridad se halla en condiciones de demostrar que la publicación puede perjudicar gravemente a los intereses legítimos de las CCEE, comunicará por escrito su decisión al funcionario en el plazo de treinta días hábiles a contar desde la recepción de la notificación. En el supuesto de que no se notifique decisión alguna en dicho plazo, se considerará que la autoridad facultada no opone objeción alguna.

D) El derecho a la no discriminación por razones de edad

(ni de sexo o de raza)

Debido al gran número de quejas recibidas de los ciudadanos que eran excluidos de los concursos de reclutamiento por razón de la edad, el Defensor del Pueblo Europeo inició una investigación de oficio en $1997^{76}$ sobre los límites de edad en los procedimientos de integración en la función pública comunitaria ${ }^{77}$.

El entonces Defensor del Pueblo Europeo, Jacob Söderman, dio a la Comisión Europea hasta el 31 de octubre de 2000 para informarle de las me-

75 Reglamento (CE/EURATOM) n. ${ }^{\circ}$ 2148/2003 del Consejo de 5 de diciembre de 2003 (DOCE L 323, de 10 de diciembre de 2003).

76 Investigación de oficio sobre la aplicación de los límites de edad: Decisión del Pueblo Europeo en el asunto 626/97/BB, de 4 de noviembre de 1998.

77 Los límites variaban entre 35, 40, 45 y 55 años, según la institución y la oposición de la que se tratara. 
didas concretas adoptadas en relación con los límites de edad en los procedimientos de contratación de la UE. La recomendación del Defensor del Pueblo Europeo venía más de dos años después de que la Comisión le informara de que iba a poner fin a la discriminación por razones de edad.

Durante la investigación, tanto la Comisión como el Parlamento decidieron aumentar el límite de edad de los participantes en sus concursos-oposición a 45 años. Y en marzo de 1998, la Comisión informó al Defensor del Pueblo de que había decidido suprimir los límites de edad en su política de contratación, y que tenía la firme voluntad de que esta decisión fuera adoptada por otras instituciones con el fin de alcanzar un acuerdo interinstitucional. Ante la falta de progresos, y teniendo en cuenta que la Carta de los Derechos Fundamentales de la Unión Europea Carta proclama el derecho de todos a buscar un empleo (art. 15) y el derecho a no ser discriminado por motivos de edad (art. 21), el Defensor del Pueblo Europeo decidió abrir una segunda investigación de oficio ${ }^{78}$, con el objetivo de contribuir a que los derechos establecidos en la Carta constituyan una realidad para los ciudadanos europeos: "No respetar los derechos de la Carta constituye un caso de mala administración, y mi trabajo consiste en combatir la mala administración", afirmó Söderman. En su Decisión de junio de 2002, el Defensor del Pueblo Europeo comunicó que quince instituciones y organismos de la UE, incluyendo al Parlamento Europeo, a la Comisión, al Banco Central Europeo, al Comité de las Regiones y a EUROPOL $^{79}$, habían confirmado que en sus procedimientos de selección de personal no se utilizaban ya criterios de edad. Por su parte, cinco instituciones y organismos admitieron que continuaban aplicando límites de edad en sus procedimientos de selección de personal. Se trataba del Tribunal de Cuentas, el Tribunal de Justicia, el Consejo, el Comité Económico y Social y la Oficina de Armonización del Mercado Interior. Sus Secretarios Generales sostenían que los límites de edad estaban justificados sobre la base de una sólida gestión financiera. Indicaban, entre otros argumentos, que los trabajadores jóvenes son más productivos y adaptables, están más dispuestos a viajar y existen menos probabilidades de que se ausenten del trabajo.

No obstante, a partir de la puesta en funcionamiento en 2003 de la Oficina Europea de Selección de Persona ${ }^{\beta 0}$, se suprimieron dichos límites en los

78 Segunda investigación de oficio sobre la aplicación de los límites de edad: Decisión del Defensor del Pueblo Europeo en el asunto OI/2/2001/(BB)OV, de 27 de junio de 2002.

79 Parlamento Europeo, Comisión Europea, Banco Central Europeo, Banco Europeo de Inversiones, Comité de las Regiones, EUROPOL, Fundación Europea para la Mejora de las Condiciones de Vida y de Trabajo, Agencia Europea del Medio Ambiente, Observatorio Europeo de la Droga y las Toxicomanías, Oficina Comunitaria de Variedades Vegetales, Agencia Europea para la Seguridad y la Salud en el Trabajo, Fundación Europea de Formación, Observatorio Europeo de Fenómenos Racistas y Xenófobos, Agencia Europea para la Evaluación de Medicamentos, Centro de Traducción de los Órganos de la Unión Europea, Centro Europeo para el Desarrollo de la Formación Profesional

80 Decision (2002/621/EC) of the Secretaries General of the European Parliament, the Council and the Commission, the Registrar of the Court of Justice, the Secretaries General of the Court of Auditors, the Economic and Social Committee and the Committee of the Regions, and the repre- 
concursos abiertos. Así pues, como resultado de la presión ejercida por el Defensor del Pueblo, la promoción de la igualdad de trato en la selección de personal ha experimentado un notable avance en los últimos años, no sólo por la supresión de los límites de edad, sino también por las medidas orientadas a promover una representación más equilibrada por sexo u origen étnico.

\section{FACULTADES DE INVESTIGACIÓN}

El Defensor del Pueblo Europeo dispone de amplios poderes de investigación. De hecho, el Tratado de la Unión Europea de 1992, y ahora el Tratado de Funcionamiento de la Unión Europea no establece ningún límite para llevar a cabo las investigaciones que considere necesarias — bien por iniciativa propia, bien como consecuencia de una reclamación - para aclarar todo posible caso de mala administración en la actuación de las instituciones, órganos u organismos de la Unión, salvo que los hechos alegados sean o hayan sido objeto de un procedimiento jurisdiccional. Lógicamente, deberá informar de ello a la institución u órgano afectado, que podrá comunicarle cualquier observación útil.

Sin embargo, el Estatuto del Defensor del Pueblo Europeo de 1994, al desarrollar el procedimiento de investigación, introducía algunas restricciones a sus facultades de investigación. Finalmente, en junio de 2008, y después de una intensa labor del Defensor del Pueblo y del Parlamento Europeo a favor de la eliminación de dichas restricciones, a raíz de un informe de la Comisión de Asuntos Constitucionales (presentado por la eurodiputada Anneli Jäätteenmäki), el Parlamento Europeo adoptó una Decisión ${ }^{81}$ por la que se revisaba dicho Estatuto, que entró en vigor el 31 de julio de 2008.

Las dos modificaciones más importantes potencian las prerrogativas de investigación del Defensor del Pueblo. En primer lugar, en la actualidad el Defensor del Pueblo tiene pleno acceso durante sus investigaciones a los documentos que se encuentren en poder de las instituciones y órganos de la UE, que ya no pueden negarse a dar a conocer documentos por motivos de secreto "debidamente justificados". En segundo lugar, los funcionarios de la UE que prestan testimonio ante el Defensor del Pueblo ya no están obligados a expresarse "en nombre de la administración de la que dependan y conforme

sentative of the European Ombudsman, de 25 de julio 2002, on the organisation and operation of the European Communities Personnel Selection Office (DO L 197, de 26 de Julio de 2002).

81 Decisión 2008/587/CE del Parlamento Europeo, de 18 de junio de 2008, por la que se modifica la Decisión 94/262 sobre el Estatuto del Defensor del Pueblo Europeo y sobre las condiciones generales del ejercicio de sus funciones (DO L 189, de 18 de junio de 2008). En consecuencia, el 3 de diciembre de 2008, el Defensor del Pueblo Europeo revisó su Decisión sobre las disposiciones de aplicación para reflejar las modificaciones que había sufrido el Estatuto y tener en cuenta la experiencia adquirida desde 2004, año en que las disposiciones fueron modificadas por última vez. Esta modificación entró en vigor el 1 de enero de 2009. 
a sus instrucciones". También se esclarecen y consolidan las disposiciones adoptadas para que el Defensor del Pueblo mantenga la confidencialidad de los documentos y la información ${ }^{82}$.

En tal sentido, y de acuerdo a la nueva regulación, hay que señalar que las instituciones y órganos comunitarios están obligados a facilitar al Defensor del Pueblo, en un plazo razonable, las informaciones requeridas y darle ac-

82 Las restricciones establecidas por el Estatuto fueron duramente criticadas por el Defensor el Pueblo en su Informe Anual 1998 al Parlamento Europeo, que las calificó de innecesarias, e incluso inapropiadas". El entonces Defensor del Pueblo, J.Söderman, consideró que "tras la idea de una investigación del Defensor del Pueblo, los ciudadanos confían en que éste tenga acceso a todo los hechos y documentos relevantes, aun cuando la información no pueda hacerse completamente pública por estar clasificada. Los ciudadanos deberían tener la seguridad de que las investigaciones del Defensor del Pueblo no están limitadas, y que éste puede llevar a cabo todas las declaraciones e inspeccionar los expedientes que considere necesarios".

Y en cuanto a las restricciones establecidas para las audiciones a los testigos las consideró «inaceptables, porque, si se toman literalmente — argumentaba Söderman- podrían incluso obligar a un testigo a mentir (por ejemplo, para ocultar un caso de fraude) si así se ha ordenado por parte de sus superiores en la administración (...) De hecho, el razonamiento que sustenta la actual disposición del Estatuto resulta un obstáculo para la correcta tramitación de los asuntos de corrupción y fraude dentro de la administración europea" (Informe Anual del Defensor del Pueblo Europeo 1998, págs. 12 y 13). Esta restricción también fue cuestionada por la doctrina que ha considerado que este sometimiento del funcionario a las instrucciones de la administración comunitaria "fomenta un espíritu de cuerpo y se sitúa más allá del deber de lealtad del funcionario hacia la administración, para entrar en el terreno de una especie de testimonio dirigido" (STEENBJERG KOLZE, cit. pág. 83).

Desde luego, es evidente que estas disposiciones del Estatuto del Defensor del Pueblo rezumaban demasiados recelos hacia la función del Defensor del Pueblo y articulaban una importante batería de obstáculos en el desarrollo de sus investigaciones, hasta el punto de que A. Gil-Robles las calificó de "cláusulas secantes" (GIL RoBles, A.: "Las relaciones del Parlamento Europeo con otras instituciones comunitarias de control y fiscalización", cit., pág. 310).

En consecuencia, el Defensor del Pueblo propuso una modificación del artículo 3.2 de su Estatuto en el sentido de eliminar las citadas restricciones. El Parlamento Europeo aprobó una Resolución el 6 de septiembre de 2001 sobre dicha modificación, basada en el Informe de la Comisión de Asuntos Constitucionales (más conocido como Informe Garrett) (Resolución del Parlamento Europeo sobre la modificación del artículo 3 del Estatuto del Defensor del Pueblo y sobre las condiciones generales de sus funciones (DO C 72E, de 21 de marzo de 2002) pág. 336 y 337. Informe de la Comisión de Asuntos Constitucionales (Ponente: Sra. Garrettt) A5-0240/2001PE 294.729 def.).

Pero la Comisión Europea — que de acuerdo con el artículo 195.4 del TCE (actual 228.2 TFUE) tiene la posibilidad de presentar un dictamen sobre el texto revisado, que requiere también la aprobación del Consejo por mayoría cualificada antes de entrar en vigor- emitió un informe negativo el 6 de marzo de 2002 (COM (2002)133 final). El Defensor del Pueblo respondió a la Comisión el 27 de junio de 2002, lamentando su criterio en contra de la propuesta de modificación y argumentando que su intención no era otra que «velar por que su Estatuto reflejara las potestades normales de toda institución moderna del Defensor del Pueblo, que constatara la deducción de las instituciones de la Unión Europea a los principios de buena administración y responsabilidad" (Informe Anual del Defensor del Pueblo Europeo 2002, pág. 26.). Desde entonces, el Defensor del Pueblo siguió solicitando la revisión de su Estatuto en todos sus Informes anuales dirigidos al Parlamento Europeo, y éste sigue insistiendo en su opinión favorable hasta lograr su modificación en 2008 (Véase a título de ejemplo el Informe Anual del Defensor del Pueblo 2006 y el Informe del Parlamento Europeo obre el Informe Anual relativo a las actividades del Defensor del Pueblo Europeo en 2006, de 26 de julio de 2007 (A6-0301/2007 final). 
ceso a la documentación relativa al caso (art.3.2 EDP). El Defensor del Pueblo podrá hacer copias del expediente completo o de documentos específicos del mismo. El Defensor del Pueblo informará al demandante de que se ha efectuado un examen (art. 5 DDP).

El acceso a información o documentos o documentos clasificados, en particular a documentos sensibles ${ }^{83}$, estará sujeto a las normas de seguridad de la institución u órgano de la Unión de que se trate. Las instituciones o los órganos que faciliten información o documentos clasificados informaran al Defensor del Pueblo de dicha clasificación (art. 3.2 EDP).

Por otra parte, el derecho genérico de acceso a la información por parte del Defensor del Pueblo incluye también el derecho de conocer la información de los Estados miembros. En este sentido, el Estatuto dispone que para dar acceso a los documentos procedentes de un Estado miembro clasificados como secretos en virtud de una disposición legislativa o reglamentaria será necesario haber obtenido el acuerdo previo de dicho Estado miembro. Y para dar acceso a los demás documentos procedentes de un Estado miembro será necesario haber advertido al Estado miembro de que se trate. En ambos casos, el Defensor del Pueblo no podrá divulgar el contenido de dichos documentos (art. 3.2 EDP).

Asimismo, aunque las investigaciones del Defensor del Pueblo Europeo no pueden tener por objeto la actuación de los Estados miembros, puede ser necesario requerir información de las autoridades nacionales. En tal sentido, éstas estarán obligadas, cuando el Defensor del Pueblo lo requiera, a facilitar, a través de las Representaciones Permanentes de los Estados miembros ante la Unión Europea, toda la información que pueda contribuir al esclarecimiento de los casos de mala administración por parte de las instituciones u órganos comunitarios, salvo en caso de que dicha información esté cubierta por disposiciones legislativas o reglamentarias relativas al secreto, o por cualquier otra disposición que impida su publicación. No obstante, en este caso, el Estado miembro implicado podrá permitir al Defensor del Pueblo el acceso a dicha información siempre y cuando se comprometa a no divulgar el contenido de la misma (art. 3.3 EDP).

El Estatuto del Defensor del Pueblo Europeo insiste de nuevo en su artículo 4.1 en el deber del Defensor del Pueblo Europeo y de su personal a no divulgar las informaciones y documentos de los que hubiera tenido conocimiento en el marco de sus investigaciones, y en particular, a no divulgar información clasificada ni documentos facilitados al Defensor del Pueblo, en es-

83 A tenor de lo dispuesto en el artículo 9 del Reglamento CE/1049/2001 (DO L 145, de 31 de mayo de 2001) "se entenderá por 'documento sensible' todo documento que tenga su origen en las instituciones o en sus agencias, en los Estados miembros, en los terceros países o en organizaciones internacionales, clasificado como 'très secret/ top secret', 'secret' o 'confidentiel', en virtud de las normas vigentes en la institución en cuestión que protegen intereses esenciales de la Unión Europea o de uno o varios Estados miembros en determinados ámbitos (relaciones internacionales, política financiera, monetaria o económica de la Unión o de uno de sus Estados miembros) y en particular, la seguridad pública, la defensa y los asuntos militares". 
pecial, documentos sensibles o documentos comprendidos en el ámbito de aplicación de la legislación comunitaria en materia de protección de datos personales ni tampoco ninguna información que pudiera causar perjuicio al que presenta la reclamación o a otras personas afectadas.

Esta exigencia "machaconamente repetida en el Estatuto de que no divulgue el contenido de los documentos a los que ha tenido acceso en el ejercicio de sus funciones" lleva a plantearse "cómo podrá informar el Defensor al Parlamento fundadamente, o articular sus recomendaciones, si no puede revelar el contenido de los documentos sobre los que trabaja en sus investigaciones, y que son precisamente la base de la queja del ciudadano europeo, así como la razón de sus recomendaciones" ${ }^{84}$.

En cuanto a la obligación de los funcionarios y otros agentes de las instituciones y órganos comunitarios a prestar declaración cuando lo solicite el Defensor del Pueblo, hasta la reforma del Estatuto en 2008, aquéllos debían expresarse en nombre de la administración de la que dependan y conforme a las instrucciones de ésta" ${ }^{85}$. Desde entonces, los funcionarios y otros agentes de las instituciones y órganos de la Unión estarán obligados a prestar declaración cuando lo solicite el Defensor del Pueblo, estando sujetos a las disposiciones pertinentes del Estatuto de los Funcionarios de las CCEE y el régimen aplicable a otros agentes comunitarios y tendrán la obligación de mantener el secreto profesional (art. 3.2. in fine EDP).

Por otro lado, el Defensor del Pueblo podrá pedir a las instituciones y órganos comunitarios que adopten medidas prácticas que le permitan llevar a cabo sus investigaciones in situ. Y podrá encargar los estudios o peritajes que estime necesarios para la realización de una investigación (art. 5.4 y 5 DDP).

Si en el marco de sus investigaciones, el Defensor del Pueblo tuviere conocimiento de hechos que considere materia de Derecho Penal, informará inmediatamente a las autoridades nacionales competentes a través de sus Representaciones Permanentes ante la Unión Europea, así como, en su caso, a la institución comunitaria a la que pertenezca el funcionario o el agente afectado; esta última podrá aplicar, en su caso, el segundo párrafo del artículo 18 del Protocolo sobre Privilegios e Inmunidades de las CCEE (art. 4.2 EDP).

El Defensor del Pueblo podrá, asimismo, informar a la institución u órgano comunitario afectado acerca de los hechos que cuestionen, desde un punto de vista disciplinario, el comportamiento de alguno de sus funcionarios o agentes (art. 4.2 EDP).

En caso de no recibir la asistencia que desee, el Defensor del Pueblo informará de ello al Parlamento Europeo, que emprenderá las gestiones oportunas (art. 3.4 EDP).

84 GIL-ROBLES, A.: "Las relaciones del Parlamento Europeo con otras instituciones comunitarias de control y fiscalización", en la obra colectiva dirigida por J.M. GIL-ROBLES, Los Parlamentos de Europa y el Parlamento Europeo, Cyan, Madrid 1997, pág. 310.

85 Antiguo artículo $3.2 \mathrm{EDP}$ 
Hay que resaltar que el Defensor del Pueblo dispondrá de las mismas facultades de investigación para las investigaciones por iniciativa propia que para las investigaciones abiertas como consecuencia de una reclamación (art. 9.2 DDP).

\section{V.1. LA RESOLUCIÓN DE LAS INVESTIGACIONES}

Si el Defensor del Pueblo determina que existe un caso de mala administración, cooperará en la medida de lo posible con la institución afectada para encontrar una solución amistosa que suprima el caso de mala administración y dé satisfacción al reclamante.

Cuando el Defensor del Pueblo considera que una cooperación de este tipo ha tenido éxito archivará el asunto mediante una decisión motivada, e informará de ello al reclamante y a la institución afectada (art. 6 EDP). Hay que señalar que muchas de las soluciones amistosas se logran cuando la institución o el órgano afectado ofrecen una compensación al reclamante; ahora bien, las ofertas de este tipo se hacen ex gratia, es decir, sin admisión de responsabilidad jurídica ni creación de un precedente.

Pero si el Defensor del Pueblo estima que no es posible una solución amistosa, puede decidir archivar el asunto mediante una decisión motivada que podrá contener un comentario crítico, cuando considera que la institución responsable ya no tiene posibilidad de remediar la mala administración, ésta no ha tenido implicaciones generales y no resulta indicado un seguimiento por parte del Defensor del Pueblo. Cuando proceda de esta forma, informará de su decisión al reclamante (art. 7 EDP).

Un comentario crítico confirma al demandante que su reclamación está justificada e indica a la institución o al órgano en cuestión que ha actuado erróneamente, contribuyendo así a evitar la mala administración en el futuro.

Asimismo, el Defensor del Pueblo puede elaborar un informe con proyectos de recomendación dirigido a la institución afectada cuando considere que es posible que ésta suprima el caso de mala administración, o que dicho caso tiene consecuencias generales. De su informe y de los proyectos de recomendación, el Defensor el Pueblo deberá enviar una copia a la institución afectada y al reclamante. La institución afectada remitirá al Defensor del Pueblo un informe motivado - que podrá consistir en la aceptación de la decisión del Defensor y en detallar las medidas adoptadas con vistas a la ejecución e los proyectos de recomendación - en el plazo de tres meses. Si el Defensor del Pueblo considera que dicho informe motivado no es satisfactorio, podrá elaborar un informe especial dirigido al Parlamento Europeo sobre el caso concreto de mala administración. Este informe especial puede contener recomendaciones, y será remitido a la institución afectada y al reclamante (art. 8 EDP). Quiero señalar que el Parlamento Europeo, en sus Resoluciones sobre los Informes Anuales del Defensor del Pueblo, considera que «si una institución se niega a seguir una recomendación incluida en un infor- 
me especial del Defensor del Pueblo, incluso después de que el Parlamento la hubiera aprobado, éste podrá usar sus competencias para incoar una acción ante el Tribunal de Justicia por el acto o la omisión objeto de la recomendación del Defensor del Pueblo".

Por otra parte, en la práctica, en aquellos casos en los que el Defensor del Pueblo considera que un proyecto de recomendación no tendría ninguna utilidad, o no parece conveniente elaborar un informe especial dirigido al Parlamento Europeo si la institución u órgano afectados no aceptan el proyecto de recomendación, el Defensor del Pueblo suele formular un comentario crítico.

Es importante recordar que las resoluciones del Defensor del Pueblo no atribuyen o niegan derechos, ni pueden anular una decisión de una institución u órgano comunitario ni obligar a éstos a indemnizar al reclamante de alguna manera. Ahora bien, esto no significa que las resoluciones del Defensor del Pueblo Europeo no generen unos efectos determinados ante las instituciones afectadas o el Parlamento. Una resolución fundada en Derecho y emitida por una autoridad independiente como es el Defensor del Pueblo, que puede recomendar la modificación de una determinada normativa comunitaria que al ser aplicada lesiona derechos fundamentales, y poner en evidencia a las instituciones u órganos comunitarios afectados por casos de mala administración claramente demostrados, "puede resultar más devastadora que la más estricta de las sentencias judiciales". Porque al final, la administración comunitaria pretende aparecer ante la opinión pública como una estructura transparente, eficaz y cercana a lo ciudadanos europeos, y siendo consciente de su mala imagen ante éstos, no querrá deteriorarla aún más haciendo caso omiso de las recomendaciones del Defensor del Pueblo.

Y por último, podríamos plantearnos una vieja máxima del Derecho Romano: ¿Quién guarda a los guardianes?, es decir, ¿qué ocurre cuando el reclamante considera que la actuación del Defensor del Pueblo le ha ocasionado un perjuicio? ${ }^{\text {?6 }}$

Aunque ni el Tratado ni el Estatuto del Defensor del Pueblo contemplan la presentación de recursos contra las decisiones del Defensor del Pueblo en relación con la tramitación o los resultados de la investigación de una reclamación, la jurisprudencia comunitaria ha admitido que los reclamantes pueden, de acuerdo con el artículo 340 TFUE presentar demandas por daños y perjuicios en contra del Defensor del Pueblo sobre la base de una supuesta tramitación incorrecta de una reclamación por parte de éste, al igual que contra las instituciones y demás órganos comunitarios. Esta orientación jurisprudencial se inició en el año 2002 con una sentencia del Tribunal de Primera Instancia que resolvía un recurso de indemnización por responsabilidad ex-

86 Véase el comentario a un caso ocurrido en 1999 en la nota de FERRER JEFFREY, B.: "Presente y futuro del Defensor del Pueblo Europeo, guardián de la buena administración", en Revista de Derecho de la Unión Europea n. ${ }^{\circ}$ 3, 2. ${ }^{\circ}$ Semestre de 2002, pág. 350-351. 
tracontractual interpuesto por un reclamante contra el Defensor del Pueblo, y posteriormente fue confirmada por el Tribunal de Justicia de las Comunidades Europeas en 2004.

En cuanto al fondo, tanto el Tribunal de Justicia, como el Tribunal de Primera Instancia dejaron claro que «la responsabilidad extracontractual del Defensor del Pueblo sólo puede generarse si se produce un incumplimiento flagrante y manifiesto de las obligaciones que le incumbe en este ámbito" ${ }^{87}$. Y en el caso concreto que se había planteado, el Tribunal de Justicia de las Comunidades Europeas confirmó la sentencia del Tribunal de Primera Instancia, y consideró que el Defensor del Pueblo no había incumplido ninguna de sus obligaciones ${ }^{88}$, por lo que no cabía dicha responsabilidad extracontractual.

\section{LOS INFORMES ANUALES DEL DEFENSOR DEL PUEBLO EUROPEO: SU IMPACTO}

De conformidad con lo establecido en el Tratado y en el Estatuto del Defensor del Pueblo Europeo, éste deberá presentar al Parlamento Europeo un Informe Anual sobre el conjunto de sus actividades y, particularmente, sobre el resultado de sus investigaciones. El Informe Anual podrá contener todas las recomendaciones que el Defensor del Pueblo considere oportunas para dar cumplimiento a su mandato.

El Informe Anual es, en primer lugar, objeto de debate en la Comisión de Peticiones del Parlamento Europeo, que emite un Informe que es enviado también al Pleno del Parlamento Europeo para su debate ${ }^{89}$. Posteriormente, el Informe Anual del Defensor del Pueblo es sometido al Pleno del Parlamento que lo aprueba mediante una Resolución, en la cual el Parlamento Europeo hace una valoración del informe y hace expresas una serie de peticiones a las instituciones y órganos comunitarios en el sentido de cooperar de manera constructiva con el Defensor del Pueblo en todas las etapas del procedimiento, aplicar sus proyectos de recomendación, y respetar las observaciones críticas, teniéndolas en cuenta en sus futuras acciones.

Pues bien, según el Informe Anual que el Defensor del Pueblo remitió al Parlamento Europeo en enero de 2010, relativo a sus actividades en el año 2009, se registraron 3.098 reclamaciones frente a las 3.406 de 2008. En el mis-

87 Sentencia del Tribunal de Primera Instancia de 10 de abril de 2002, Lamberts vs Defensor del Pueblo, T-209/00, Rec. 2002.

88 Sentencia del Tribunal de Justicia de las CCEE de 23 de marzo de 2004 en el asunto C234/02, Defensor del Pueblo vs Frank Lamberts.

89 A título de ejemplo, véanse los Informes de la Comisión de Peticiones del PE sobre el Informe anual relativo a las actividades del Defensor del Pueblo Europeo en 1997 (Ponente: E.Newman) (PE 226.262/def., de 26 de junio de 1998) y en 2006 (Ponente: L. Sbarbati) PE 390.565 v02-00, de 26 de julio de 2007. 
mo sentido, el número de reclamaciones tramitadas disminuyó tanto en términos absolutos como relativos: de 3.346 a $3.119^{90}$.

A lo largo de 2009 se iniciaron un total de 293 investigaciones nuevas a partir de las reclamaciones recibidas. Y además, se iniciaron 3 investigaciones de oficio.

$\mathrm{Al}$ igual que en años anteriores, una amplia mayoría de las reclamaciones, en concreto 191 (el 56\% del total) se referían a la Comisión Europea. Esto es totalmente normal si tenemos en cuenta que la Comisión es la principal institución comunitaria que toma decisiones que afectan directamente a los ciudadanos y a las empresas. Además, hubo 38 investigaciones (11\%) relativas al Parlamento Europeo, 30 (9\%) a la Oficina Europea de Selección de Personal, 12 (4\%) al Consejo de la Unión Europea, 9 (3\%) al Tribunal de Justicia de la Unión Europea y 59 (17\%) referidas a otras instituciones y órganos comunitarios.

Por lo que se refiere a los resultados de sus investigaciones, el Defensor del Pueblo constató en 58 asuntos que no existía mala administración; 179 fueron resueltos por la propia institución u órgano afectado o archivadas tras obtener una solución amistosa. Se halló mala administración en 53 casos. Se dirigieron 35 comentarios críticos a instituciones y órganos comunitarios y 1 proyecto de recomendación.

El Parlamento Europeo debe dar la mayor difusión a estos informes y hacer un seguimiento continuado de las recomendaciones más relevantes, seguimiento que también realiza el propio Defensor del Pueblo.

En la práctica, el impacto de estos informes está en la publicidad que se da a las críticas que hace el Defensor del Pueblo Europeo sobre la actuación de la administración comunitaria por parte del Parlamento Europeo, y cómo no, por la prensa. Esta publicidad representa una importante "Sanción" para las instituciones y órganos comunitarios.

\section{LAS RELACIONES DEL DEFENSOR DEL PUEBLO EUROPEO CON LOS DEFENSORES DEL PUEBLO Y ÓRGANOS SIMILARES: LA RED EUROPEA DE DEFENSORES DEL PUEBLO}

La Red Europea de Defensores del Pueblo engloba con carácter voluntario a los Defensores del Pueblo nacionales y regionales y a los órganos similares de los Estados miembro de la Unión Europea, a los Defensores del Pueblo nacionales de Noruega e Islandia y de los países candidatos a la adhesión, así como al Defensor del Pueblo Europeo y a la Comisión de Peticiones del Parlamento Europeo.

90 La categoría estadística "tramitada" significa que la reclamación está dentro del mandato del Defensor del Pueblo, cumple los criterios de admisibilidad, y la investigación se ha completado. Debido al tiempo requerido para ello, el número de reclamaciones "tramitadas" en un año determinado es diferente del número de reclamaciones "registradas" en el mismo año. 
Esta Red fue creada en 1996 y se ha ido desarrollando desde entonces hasta convertirse en una eficaz herramienta de colaboración para los defensores del pueblo y sus colaboradores. Además, constituye un eficaz mecanismo de cooperación en la tramitación de las reclamaciones remitidas al Defensor del Pueblo Europeo, ya que le permite tramitar aquellas que están fuera de su ámbito de competencia de una forma rápida y eficaz.

La Red permite también compartir e intercambiar las experiencias y mejores prácticas de sus miembros a través de seminarios, reuniones, en un boletín periódico, un foro de internet y en una publicación electrónica diaria.

Precisamente en el VI Seminario de Defensores del Pueblo nacionales de los Estados miembros de la Unión Europea y de los países candidatos, celebrado en Estrasburgo los días 14, 15 y 16 de octubre de 2007, se adoptó una Declaración ${ }^{11}$ con el fin de dar a conocer mejor la labor que realizan los Defensores del Pueblo, así como clarificar los servicios que prestan a los reclamantes sobre cuestiones relativas al ámbito de aplicación del Derecho de la Unión Europea.

TITLE: The European Ombudsman: 15 years later.

ABSTRACT: The aim of this article is to study the important and decisive role that the figure of the European Ombudsman has played in the European arena since 1992. On one hand, the political power of this figure has made possible a real approach to the European citizens to the decisory organs. On the other hand, it has reinforced the system of protection of the Fundamental Rights with in the legal framework of the Union. These facts make possible for the European Ombudsman to investigate the maladministration in the activities of the institutions and bodies of the European Union.

RESUMEN: El objeto de este trabajo es el estudio del importante papel desarrollado por el Defensor del Pueblo Europeo desde su reconocimiento en el Tratado de la Unión Europea. Esta figura ha hecho posible un mayor acercamiento a los ciudadanos de las instancias decisorias de la Unión, y sobre todo, ha reforzado el sistema de protección de los derechos fundamentales en el ordenamiento jurídico de la Unión, ya que puede investigar los casos de mala administración de las instituciones y órganos comunitarios.

KEY WORDS: The European Ombudsman. Maladministration. Fundamental rights. Citizens.

Palabras clave: Defensor del Pueblo Europeo. Mala administración. Derechos fundamentales. Ciudadanos.

FECHA DE RECEPCIÓN: 21.06.2010. FECHA DE ACEPTACIÓN: 28.07.2010.

91 Esta Declaración está incluida en el Informe Anual 2007 del Defensor del Pueblo Europeo: Annual Report 2007, pág. 130-133. 